Article type : Review Article

\title{
Neurophysiological mechanisms of chiropractic spinal manipulation for spine pain.
}

\author{
C. Gevers-Montoro ${ }^{1-3}$, B. Provencher ${ }^{1,2}$, M. Descarreaux ${ }^{1,4}$, A. Ortega de Mues ${ }^{3}$ and M. \\ Piché $^{1,2 *}$
}

${ }^{1}$ Department of Anatomy, Université du Québec à Trois-Rivières, 3351 Boul. Des Forges, C.P. 500, Trois- Rivières, QC, Canada, G9A 5H7.

${ }^{2}$ CogNAC Research Group, Université du Québec à Trois-Rivières, 3351 Boul. Des Forges, C.P. 500, Trois-Rivières, QC, Canada, G9A 5H7.

${ }^{3}$ Madrid College of Chiropractic - RCU María Cristina, Paseo de los Alamillos 2, 28200 San Lorenzo de El Escorial, Madrid, Spain.

${ }^{4}$ GRAN Research Group, Université du Québec à Trois-Rivières, 3351 Boul. Des Forges, C.P. 500, Trois-Rivières, QC, Canada, G9A 5 H7.

\section{*Corresponding author:}

Mathieu Piché, DC, $\mathrm{PhD}$

Department of Anatomy

Université du Québec à Trois-Rivières

3351 boul. des Forges, C.P. 500

Trois-Rivières, Québec, Canada G9A 5H7

Ph.: 819-376-5011 Ext. 3998

Fax: 819-376-5204

This article has been accepted for publication and undergone full peer review but has not been through the copyediting, typesetting, pagination and proofreading process, which may lead to differences between this version and the Version of Record. Please cite this article as doi: 
E-mail: mathieu.piche@uqtr.ca

Running head: Mechanisms and effectiveness of spinal manipulation

Category: Review

Funding sources: The contribution of Carlos Gevers Montoro was supported by the Fondation de Recherche en Chiropratique du Québec. The contribution of Benjamin Provencher was supported by the Canadian Institutes of Health Research and the Fonds de Recherche du Québec en Santé (FRQS). The contribution of Mathieu Piché was supported by the Fondation de Recherche en Chiropratique du Québec and the Fonds de Recherche du Québec en Santé (FRQS).

Conflicts of interest disclosure: The authors report no financial or other relationship that may lead to any conflict of interest.

Significance: Spinal manipulation inhibits back and neck pain partly through spinal segmental mechanisms and potentially through peripheral mechanisms regulating inflammatory responses. Other mechanisms remain to be clarified. Controls and placebo interventions need to be improved in order to clarify the contribution of specific and nonspecific effects to pain relief by spinal manipulative therapy.

This article is protected by copyright. All rights reserved 


\section{Abstract}

Together, neck pain and back pain are the first cause of disability worldwide, accounting for more than $10 \%$ of the total years lived with disability. In this context, chiropractic care provides a safe and effective option for the management of a large proportion of these patients. Chiropractic is a healthcare profession mainly focused on the spine and the treatment of spinal disorders, including spine pain. Basic studies have examined the influence of chiropractic spinal manipulation on a variety of peripheral, spinal, and supraspinal mechanisms involved in spine pain. While spinal cord mechanisms of pain inhibition contribute at least partly to the pain-relieving effects of chiropractic treatments, the evidence is weaker regarding peripheral and supraspinal mechanisms, which are important components of acute and chronic pain. This narrative review highlights the most relevant mechanisms of pain relief by spinal manipulation and provides a perspective for future research on spinal manipulation and spine pain, including the validation of placebo interventions that control for placebo effects and other non-specific effects that may be induced by spinal manipulation.

Keywords : Low back pain; neck pain; pain inhibition; placebo; spinal manipulative therapy; manual therapy. 


\section{Introduction}

Spine pain of musculoskeletal origin can affect the cervical, thoracic, or lumbar regions. Its duration may range from an acute episode of a few days or weeks to chronicity over several years (Borghouts et al., 1998; Urits et al., 2019). Low back pain (LBP) is the leading contributor to disability, followed closely by neck pain (NP) (James et al., 2018; Urits et al., 2019). Together, back pain and neck pain are responsible for more than $10 \%$ of the total years lived with disability worldwide (James et al., 2018). Spine pain can originate from myofascial tissues, facet joints, intervertebral discs, spinal ligaments, and other less common causes (Urits et al., 2019; Vlaeyen et al., 2018). However, it remains challenging to identify the source of pain in individual cases (Hartvigsen et al, 2018; Vlaeyen et al, 2018). Accordingly, chronic low back and neck pain are considered non-specific in a large majority of cases, meaning the pain cannot be attributed to a specific origin or to a pathology detectable with imaging methods (Borghouts et al., 1998; Vlaeyen et al., 2018). Recently, both chronic non-specific low back and neck pain have been classified as chronic primary pain syndromes under the new International Association for the Study of Pain (IASP) classification of chronic pain for the latest revision of the International Classification of Diseases (ICD-11) (Nicholas et al., 2019; Treede et al., 2019; Vlaeyen et al., 2018). Due to the dramatic impact of acute spine pain and chronic primary spine pain on individuals and society (Hartvigsen et al., 2018; James et al., 2018; Urits et al., 2019; Vlaeyen et al., 2018), safer and more effective interventions are needed. Among conservative approaches, chiropractic spinal manipulative therapy (SMT) is one of the potentially effective interventions for these conditions.

Chiropractic is a healthcare profession in the field of musculoskeletal health. Its main focus is on spine function and disorders, including spine pain (Brown, 2016; Murphy et al., 2011). Chiropractors use a variety of conservative approaches, including SMT as the most common intervention (Beliveau et al, 2017). SMT involves the application of spinal manipulation (SM; also referred to as chiropractic adjustment in the field of chiropractic) over several sessions (W.H.O., 2005). During a chiropractic SM, clinicians apply a controlled force of a specific magnitude and orientation to a targeted spinal segment (Herzog, 2010). The concept of SM specificity has been challenged by research showing that forces cannot be effectively directed to a single target segment and in a precise direction (Bereznick et al., 2002; Herzog et al., 2001; Ross et al., 2004). Nonetheless, the contact site may influence the neurophysiological responses to SM (Nim et al., 2020; Reed et al., 2015; Reed and Pickar, 2015). Whether biomechanical characteristics or neurophysiological mechanisms of SM 
differ when applied by different providers remains unknown. Here, the neurophysiological mechanisms of SM are reviewed from a chiropractic perspective (Henderson, 2012), although informed by studies where SM was performed by chiropractors and other practitioners.

SM generally consists in the application of a mechanical force on spinal joints in the form of a high velocity and low amplitude (HVLA) thrust preceded by a slower preload phase (Pickar and Bolton, 2012; Reed et al., 2014). Both the preload and thrust phases impact paraspinal muscle responses (Nougarou et al., 2013; Reed et al., 2014) and load articular tissues, including the intervertebral discs, joint capsules, and ligaments (Funabashi et al, 2017). Previous studies suggest that the mechanical force applied during SM alters spinal biomechanics and activates paraspinal sensory terminals (Bialosky et al., 2009a; Gyer et al., 2019; Pickar and Bolton, 2012). It has been proposed that this afferent fiber stimulation initiates a cascade of peripheral and central neurophysiological effects (Bialosky et al, 2009a; Pickar and Bolton, 2012). In turn, these effects may underlie some of the clinical outcomes observed with SMT (Bialosky et al., 2009a; Pickar and Bolton, 2012). A comprehensive model including biomechanical and neurophysiological mechanisms for pain relief induced by manual therapy has been proposed (Bialosky et al, 2018; Bialosky et al, 2009a). Nonetheless, the exact neurophysiological mechanisms by which SM relieves pain remain unclear (Gyer et al., 2019). This is particularly important for pain affecting the spine, as most of the current Clinical Practice Guidelines (CPG) recommend the use of SMT for the management of LBP and NP (Bussieres et al., 2018; Cote et al., 2016; Foster et al., 2018; Kjaer et al., 2017; Qaseem et al., 2017).

The aim of this review is to discuss the pain-relieving mechanisms of SM for spine pain. In addition, a perspective on challenges and future directions for research on chiropractic SM and spine pain will be presented.

\section{Mechanisms of pain relief by spinal manipulation}

Previous studies on pain relief by SM have reported effects on the peripheral nervous system, spinal cord mechanisms, and supraspinal processes (Bialosky et al., 2009a; Gyer et al, 2019). In this section, the mechanisms of pain inhibition by SM will be reviewed critically, based on the location of the effect within the nociceptive system. A schematic summary of these potential mechanisms is presented in Figure 1. A summary of the most relevant mechanisms with supporting evidence is also presented in Table 1. 


\section{Peripheral mechanisms}

Spine pain may be caused by an injury to musculoskeletal tissues of the spine (Vlaeyen et al., 2018) through direct activation of nociceptive afferents. In acute and chronic inflammatory states, spine pain may be modulated by sensitization and desensitization of nociceptors by pro- and anti-inflammatory mediators. Here we will discuss how SM may produce pain relief by modulating inflammatory processes and sensitization in peripheral tissues.

\subsection{Cortisol release}

Pain may be inhibited by hormones with a known anti-inflammatory function on the periphery, such as cortisol (Hannibal and Bishop, 2014; Hench et al., 1950; Saldanha et al., 1986). Cortisol levels rise in anticipation and as a response to acute stressful situations (Hannibal and Bishop, 2014; Mason et al., 1973). It has been proposed that stress induced by SM or its anticipation, particularly when applied to the cervical spine, may partially underlie its pain inhibitory effects (Kovanur-Sampath et al., 2017a; Plaza-Manzano et al., 2014; Valera-Calero et al., 2019; Whelan et al., 2002). However, the studies reported inconsistent changes in plasma or salivary cortisol levels after SM. Up to five minutes after SM, cortisol levels either increased (Plaza-Manzano et al., 2014; Valera-Calero et al., 2019), decreased (Kovanur-Sampath et al., 2017a) or remained unchanged (Lohman et al., 2019; Whelan et al., 2002) in healthy participants and patients with NP. Moreover, the short-term effects of SM were not significantly different from those observed with mobilization techniques (ValeraCalero et al., 2019). These conflicting results may be due to methodological discrepancies, including the participants' characteristics (only males vs. only females; healthy volunteers vs. patients with acute pain vs. patients with chronic pain), the site of SM (cervical vs. thoracic), cortisol sampling methodology (serum vs. saliva) and its collection (immediately following the intervention vs. 5 minutes or longer after SM). These inconsistencies prevent drawing any conclusion on the effect of SM on cortisol. This does not rule out the effect, but more highquality studies with standardized methodology are needed to reach a conclusion. Thus far, the conflicting findings do not support the release of cortisol as a specific pain-relieving mechanism of SM.

\subsection{Peripheral inflammation and sensitization}

Following cervical SM, an increase in plasmatic substance $\mathrm{P}$ was reported, while pressure-pain sensitivity decreased (Kovanur-Sampath et al., 2017b; Molina-Ortega et al., 
2014). The authors proposed that augmented substance $P$ may underlie the hypoalgesic effects of SM, based on previous reports showing that substance $\mathrm{P}$ can inhibit nociceptive transmission in the spinal cord via feedforward mechanisms (Nakatsuka et al., 2005; Wu et al, 2005). However, this contrasts with the large body of evidence that describes substance $\mathrm{P}$ as a pro-nociceptive neuromodulator (Dickenson, 1995; Hackel et al, 2010; Van Der Kleij and Bienenstock, 2007). Peripheral inflammation and tissue injury are associated with a release of substance P (Dickenson, 1995; Hackel et al., 2010; Van Der Kleij and Bienenstock, 2007). In turn, substance $P$ is involved in neurogenic inflammation, hyperalgesia, and allodynia (Hackel et al., 2010). Both its peripheral and central release by primary afferents seems to be essential to experience moderate to intense pain (Cao et al., 1998). Also, elevated cerebrospinal fluid levels of substance $\mathrm{P}$ were observed in patients with chronic pain, likely reflecting levels in the spinal cord (Almay et al., 1988; Russell et al., 1994). Rather than a hypoalgesic mechanism, the increase in plasmatic substance P levels following SM may thus reflect a pro-inflammatory response due to spine tissue deformation, which has been shown to activate integrins, and in turn up-regulate substance $\mathrm{P}$ expression (Zhang et al., 2017). On the basis of the well-established pro-nociceptive and pro-inflammatory role of substance P, the hypothesis that it may contribute to pain relief by SM is unlikely.

Nociceptive fibers may be sensitized by reactive oxygen species (ROS) in tissues under oxidative stress resulting from acute injury (Westlund et al., 2010). In animal models, ROS such as hydrogen peroxide or nitric oxide have been shown to activate TRP (transient receptor potential nociceptor) channels, mediating pain and inflammatory changes (Westlund et al., 2010). In a rat model of immobilization-induced tactile allodynia, SM applied with a hand-held mechanical device prevented an increase in plasmatic ROS while improving indices of nerve function and allodynia (Duarte et al., 2019). In line with these findings, an increase in serum levels of antioxidant enzymes was reported after a 5-week treatment that included SM in patients with chronic spine pain (Kolberg et al., 2015). Future research is needed to examine whether these mechanisms contribute specifically to the pain-relieving effects of SM in patients with acute and chronic spine pain.

Cytokines and chemokines are immune regulatory substances that can induce inflammation and contribute to nociception (Abbadie et al, 2003; Marchand et al., 2005; Sommer and Kress, 2004). In patients with LBP, pro-inflammatory mediators are involved in the sensitization of nociceptors and their inflammatory profiles vary depending on pain duration (Teodorczyk-Injeyan et al, 2018; Teodorczyk-Injeyan et al., 2019). Preliminary 
results suggest that SM may reduce pro-inflammatory responses (Roy et al., 2010; Teodorczyk-Injeyan et al., 2006; Teodorczyk-Injeyan et al., 2018), which in turn may produce pain relief through changes in peripheral inflammation and nociceptor sensitization.

The current literature suggests that SM may reduce pro-nociceptive or proinflammatory mediators that are increased during spine pain (Duarte et al., 2019; Roy et al., 2010; Teodorczyk-Injeyan et al, 2006). This may limit peripheral sensitization and produce pain relief (Kolberg et al., 2015; Teodorczyk-Injeyan et al., 2018). Although the quality of the evidence on the influence of SM on biological markers was considered to be moderate (Kovanur-Sampath et al., 2017b), the current available results are not consistent and their interpretation does not always provide plausible pain-relieving mechanisms that are specific to SM. Future high-quality and well-controlled studies including mechanistic trials are needed to provide support to this line of research.

\section{Spinal cord mechanisms}

Behavioral studies indicate that SM can decrease pain sensitivity in tissues linked anatomically to the spinal cord segment influenced by SM (Alonso-Perez et al., 2017; Bialosky et al., 2008; Bialosky et al., 2009b; de Camargo et al., 2011; Dorron et al., 2016; Fernandez-Carnero et al., 2008; Fernandez-de-las-Penas et al., 2007; Fryer et al., 2004; George et al., 2006; Laframboise et al., 2016). This suggests that the pain inhibitory effect of SM may rely, at least in part, on segmental mechanisms. This hypothesis was examined in several studies that will be discussed in the following sections.

\subsection{Segmental inhibition of nociceptive processes by spinal manipulation}

The hypothesis that SM modulates pain thresholds and sensitivity in body regions related to the spinal segment influenced by SM is supported by systematic reviews and metaanalyses (Coronado et al., 2012; Honore et al., 2018; M. Millan et al., 2012). The duration and size of these effects are still unclear, although the available evidence suggests that they are transient, lasting less than ten minutes (Honore et al., 2019). A consistent finding is that SM has a more favorable and significant effect on segmental pain thresholds in comparison to inactive control or sham SM. Similar effects were observed with interventions such as nonthrust SM or mobilization (Alonso-Perez et al., 2017; Fryer et al., 2004; Honore et al., 2018; M. Millan et al., 2012; Salom-Moreno et al, 2014; Thomson et al., 2009). In healthy 
volunteers, no significant differences were observed before and after applying cervical, thoracic or lumbar SM compared with mobilization on pressure pain thresholds (PPTs) (Alonso-Perez et al., 2017; Fryer et al., 2004; Thomson et al., 2009). Moreover, in patients with chronic NP, Salom-Moreno et al. reported similar small effects of thoracic SM and mobilization on PPTs (Salom-Moreno et al., 2014). The evidence comparing SM and mobilization is still scarce. Yet, it suggests that both interventions have comparable effects on segmental pressure pain sensitivity. It remains to be determined how they compare on other effects and mechanisms described below.

The effects of SM on PPTs around the SM application site or in a related dermatome have been assessed in several studies (Alonso-Perez et al., 2017; de Camargo et al., 2011; Dorron et al., 2016; Fernandez-Carnero et al., 2008; Fernandez-de-las-Penas et al., 2007; Laframboise et al., 2016). Following a single cervical SM in healthy volunteers, PPTs were increased (i.e. pain sensitivity was decreased) in the dermatome corresponding to the level of application of SM (Alonso-Perez et al., 2017; Fernandez-de-las-Penas et al., 2007). Similar findings were observed in patients with musculoskeletal pain (Fernandez-Carnero et al., 2008). Regional effects have also been reported for PPTs of myofascial tissues innervated by a spinal segment (myotome) related to the spinal level on which SM was applied (de Camargo et al., 2011; Dorron et al., 2016; Laframboise et al., 2016).

In spite of this consensus on segmental effects of SM, it should be noted that two recent studies using a single-blinded placebo-controlled design obtained conflicting results (Aspinall et al., 2019a; Honore et al., 2020). The quality of studies on segmental hypoalgesia resulting from SM is variable. For musculoskeletal pain conditions, the quality was considered to be low (Aspinall et al., 2019b) and for healthy volunteers, the quality was rated as moderate to high (Coronado et al., 2012; Honore et al., 2018). Most studies showed a higher risk of bias due to the lack of appropriate blinding of participants, care providers and/or experimenters (Coronado et al., 2012). Future systematic reviews including highquality studies may thus change the current conclusions.

A recent study indicates that the effects of SM depend on its application site ( $\mathrm{N}$ im et al, 2020). In this trial, patients with chronic LBP were randomly allocated to one of two groups, receiving SMT targeted either at the stiffest segment or at the segment with the highest mechanical pain sensitivity. Stiffness and LBP intensity were not significantly different between groups. However, PPTs were significantly increased immediately after SM 
at the most sensitive segment ( $\mathrm{N}$ im et al., 2020). This supports the segmental effects of SM on pain-related processes, which may rely on the modulation of central sensitization (Jordon et al, 2017), as discussed below.

Animal models allow the use of invasive methods that provide insight on specific mechanisms that influence nociceptive processes and pain behaviors. They also provide highquality data on the dose-response relationship of a specific intervention (Hackam and Redelmeier, 2006). These data are still scarce in SM research (Pasquier et al., 2019), but can be obtained with mechanical devices that deliver SM-like forces. Mechanically-assisted SM allows for regulation of the applied forces or force-time profiles (Descarreaux et a1., 2013), which can be standardized for the animal's body (Reed et al, 2013). In a study by Reed and colleagues, a mechanical device was applied with different forces ranging from $25 \%$ to $85 \%$ of a cat's body weight, to imitate forces applied during a lumbosacral SM (ranging $31 \%$ to $78 \%$ of an average human body weight) (Reed et al., 2013).

Animal data have also shown that SM-like procedures could increase mechanical pain thresholds in limb dermatomes related to the spine segments on which SM was applied (Duarte et al., 2019; Grayson et al., 2012; Onifer et al., 2015; Onifer et al., 2018). Also, segmental changes in mechanical pain thresholds were observed after sensitization via inflammatory mediators (Grayson et al., 2012; Onifer et al., 2015) or peripheral neuropathic pain (Duarte et al., 2019; Onifer et al., 2018). However, thermal pain thresholds remained unchanged by SM (Grayson et al., 2012; Onifer et al., 2018), in accordance with reports in humans. Altogether, these findings from animal studies are consistent with the segmental effects of SM. It remains to be clarified whether SM can decrease temporal summation and whether this depends on its effects on nociceptive transmission by specific afferent fibers (e.g., C fibers) or on central amplification processes such as wind-up.

\subsection{Effects of spinal manipulation on temporal summation of pain}

Sustained or repeated activation of afferent nociceptive fibers induces temporal summation of pain, the perceptual correlate of windup in the spinal cord (Price et al., 1977). More specifically, stimulation at constant C-fiber strength at or above $0.3 \mathrm{~Hz}$ elicits a progressive increase in action potential firing over the course of the stimulus, reflected in enhanced pain (Mendell and Wall, 1965; Price, 1972; Price et al., 1977). Temporal summation of pain is increased in patients with chronic pain, suggesting that $\mathrm{C}$-fiber activity is abnormally maintained in these cases (Staud et al, 2004; Staud et al., 2001). It has been 
suggested that the enhancement of these spinal responses could be critical to the development of chronic LBP (Roussel et al., 2013; Woolf, 2011).

Evidence from behavioral studies suggests that SM may exert its hypoalgesic effects through an attenuation of spinal processes related to temporal summation (Aspinall et al., 2019b; Bialosky et al., 2008; Bialosky et al., 2009b; Bialosky et al., 2014; Bishop et al., 2011a; George et al., 2006; Randoll et al., 2017). Accordingly, it was reported that SM inhibits pain evoked by a pulse train or repeated thermal and electrical stimuli associated with C-fiber activation, but not pain evoked by a single stimulus (George et al., 2006; Randoll et al., 2017). In contrast, no difference in temporal summation induced by repetitive pinprick stimulation was observed after SM compared with a validated sham in patients with LBP (Aspinall et al., 2019a). This study successfully achieved blinding, although the authors acknowledge that the sham SM may not be inert. A potential explanation for the lack of effect reported by this study is that pinprick pain is primarily mediated by larger myelinated A $\delta$ fibers (Magerl et al., 2001). Taken together, these findings suggest that SM inhibits temporal summation by modulating $\mathrm{C}$-fiber activity selectively; however, this remains to be confirmed with neurophysiological methods.

\subsection{Effects of spinal manipulation on central sensitization}

Sustained or repeated noxious stimulation that activate $\mathrm{C}$-fibers may induce synaptic plasticity in the spinal cord termed "central sensitization" (Woolf, 1983). These changes persist beyond the duration of the noxious stimulation and are associated with the development of secondary hyperalgesia (pain hypersensitivity beyond the site of injury) and allodynia (pain evoked by stimuli that are usually not painful) (Woolf, 1983, 2011). Central sensitization has been linked to the development of chronic pain syndromes (Woolf, 2011) and is considered a useful concept to describe some of the mechanisms underlying chronic primary pain (Nicholas et al., 2019; Treede et al., 2019).

A preliminary study found that SM could reduce spontaneous pain, secondary hyperalgesia and allodynia induced by topical capsaicin (Mohammadian et al., 2004), which is known to evoke central sensitization through C-fiber activation (Woolf, 2011). Interestingly, ROS in the spinal cord were found to contribute to central sensitization induced by capsaicin (Lee et al., 2007; Schwartz et al., 2008) and peripheral nerve injury (Kim et al., 2010). This effect may be mediated by the expression of pro-inflammatory cytokines in the 
spinal cord (Kim et al., 2010; Willemen et al, 2018) leading to central sensitization and chronic pain (Ji et al., 2018; Kawasaki et al., 2008).

Experimental studies have shown a modulation of peripheral ROS (Duarte et al, 2019) and cytokines (Teodorczyk-Injeyan et al., 2006) after SM. To our knowledge, only one study has assessed these changes in nervous tissue (Song et al., 2016). In this experiment, ten sessions of mechanically-assisted SM were applied to rats with neuropathic pain induced by compression of the dorsal root ganglia. Hyperalgesia and nociceptive primary afferent activity were decreased after SM (Song et al., 2016). In addition, a reduction of the proinflammatory cytokine IL-1 $\beta$ in the dorsal root ganglia and an increase of the antiinflammatory IL-10 were observed (Song et al., 2016). This warrants further research in order to determine whether SM influences these and other markers of central sensitization in the spinal cord.

\subsection{Potential propiospinal effects of spinal manipulation}

Experimental studies have reported heterosegmental changes in pain sensitivity after the application of SM for chronic primary NP (Aspinall et al., 2019b; Bishop et al., 2011a; Casanova-Mendez et al., 2014; Martinez-Segura et al., 2012; Salom-Moreno et al., 2014). In these studies, pain sensitivity was reduced in somatic tissues not directly innervated by the spinal segment influenced by SM. It has been proposed that remote hypoalgesic effects may be produced by propriospinal pathways (Bishop et al., 2011a). Animal experiments have provided evidence for propriospinal inhibition of wide-dynamic range neurons by noxious conditioning stimuli (Cadden et al, 1983). Consistent with this, it has been proposed that SM could act as a conditioning stimulus to inhibit nociceptive activity (Bialosky et al., 2009a; George et al, 2006), although evidence supporting this hypothesis is lacking. Alternatively, widespread hypoalgesic effects may be produced by supraspinal mechanisms, including nonspecific contextual effects and specific effects that can be attributed to SM (Aspinall et al, 2019b; Dorron et al., 2016; Martinez-Segura et al., 2012; Salom-Moreno et al., 2014).

\section{Supraspinal mechanisms}

Widespread reduction in mechanical pain sensitivity has been reported after SM or mobilization in patients with chronic primary NP (Martinez-Segura et al, 2012; SalomMoreno et al., 2014). These results are limited by the lack of a control group, so inferring mechanisms or effects that are caused by SM is not possible (Martinez-Segura et al., 2012; 
Salom-Moreno et al., 2014). Widespread hypoalgesia may be attributed to placebo or other non-specific effects (Aspinall et al., 2019b), but it may also reflect specific hypoalgesic mechanisms of SM involving cerebral structures and supraspinal mechanisms (M. J. Millan, 2002). However, some of the same brain areas, endogenous substances, and top-down mechanisms have also been associated with placebo analgesia (L. Colloca and Barsky, 2020; Eippert et al., 2009). Placebo effects are mainly the consequence of patients' expectations concerning their health or condition (L. Colloca and Barsky, 2020). They are not specific to one intervention and can contribute to the therapeutic effects of any treatment, including SMT (Bialosky et al., 2014; Martinez-Segura et al., 2012). As both non-specific and specific effects likely share some cerebral mechanisms, placebo-controlled neuroimaging studies may be useful to elucidate their specific contribution to hypoalgesia (L. Colloca and Barsky, 2020; Gyer et al., 2019).

The perception of pain undergoes substantial processing at supraspinal levels, where multiple brain areas contribute to its representation and modulation (Apkarian et al., 2005; M. J. Millan, 2002). The "neurologic signature of pain" describes the functional imaging correlate of pain, including the most relevant areas involved in pain perception and modulation (Wager et al, 2013). Although the mechanisms are still under debate, it has been proposed that brain plasticity in areas linked to that neurologic signature could underlie the transition from acute to chronic pain, which has been studied in patients with LBP (Apkarian et al., 2011; Vlaeyen et al., 2018; Wager et al., 2013). Nonetheless, the details of the mechanisms across the brain network involved in chronic pain remain to be clarified (Apkarian et al., 2011; Baliki et al., 2014).

As an explanation for widespread hypoalgesia detected after SM, it has been proposed that SM may influence supraspinal mechanisms by activating the periaqueductal gray matter (Bialosky et al, 2009a; Gyer et al, 2019; Kovanur-Sampath et al., 2015; M. Millan et al., 2012; Savva et al., 2014). In an attempt to identify specific changes in pain-related brain activity, two studies reported that thoracic SM but not a validated sham treatment modifies the activation of pain-related regions (Sparks et al., 2017; Weber II et al., 2019). A previous study used light touch sustained for 5 minutes as a control procedure. In this study, some changes in functional connectivity between pain processing regions were specific to SM, but others were observed for both SM and the control procedure (Gay et al., 2014). However, the effects observed in the brain may reflect changes in nociceptive transmission before nociceptive inputs reach the brain and may be unrelated to descending inhibition. With a similar approach, fMRI was used to measure the neural correlates of fear of movement and 
anticipated pain from visualized exercises in chronic LBP patients, before and after SM (Ellingsen et al., 2018). Two SM sessions reduced clinical pain, fear of movement, and expected pain, and the two latter correlated with decreased brain responses evoked by observation of the back-straining exercises (Ellingsen et al, 2018). The authors posit that these findings could be driven by proprioceptive (non-conditioned) input arising from the painful area, but also by the reduction in clinical pain (Ellingsen et al., 2018). In both cases, it is difficult to conclude that any of the changes in brain activity are the direct consequence of SM and not an indirect effect of altering nociceptive transmission in the spinal cord. Accordingly, a recent systematic review suggests that most brain changes reported likely result from a change in ascending information rather than a specific supraspinal mechanism (Meyer et al., 2019). This review reported that studies on SM mechanisms potentially involving the brain were generally of low to moderate methodological quality, for which the main caveat was the credibility of the sham maneuvers (Meyer et al., 2019). With the current available data, it is not possible to draw any conclusion regarding the potential supraspinal mechanisms of SM.

\section{Placebo effects in spinal manipulative therapy}

In experimental and clinical studies, non-specific effects on pain perception include non-specific temporal changes (e.g., habituation), regression to the mean (when pain is measured at several time points), the natural course of the disease or spontaneous improvement (Kaptchuk et al., 2020). In a meta-analys is it was reported that pain reduction after SMT (96 and $67 \%$ of the total variance in acute and chronic LBP, respectively) could not be solely attributed to the specific effects of treatment (Menke, 2014). According to this analysis, the evidence for SMT is superior to sham only for chronic LBP. Consistent with this, the level of evidence supporting SMT over sham for musculoskeletal pain is considered to be low at short-term follow-up ( $<3$ months) (Scholten-Peeters et al., 2013). However, this is not unique to SMT (Menke, 2014). Indeed, 50 to $75 \%$ of responses to pharmacological treatments for chronic pain can be attributed to non-specific effects (Kaptchuk et al., 2020).

These non-specific effects can be measured and controlled for by including no-treatment groups (Hancock et al., 2006; Kaptchuk et al., 2020). When comparing sham to active treatment, oral medication does not largely outperform the placebo in patients with LBP (Machado et al., 2009; Puhl et al., 2011). The placebo effect is a non-specific effect that is 
more challenging to measure and control for in studies on SM (Hancock et al., 2006), which warrants further discussion.

\subsection{Placebo effect in studies on pain reduction by spinal manipulation}

Placebo analgesia is produced, in part, by expectations of pain reduction by a particular intervention (Benedetti et al., 1999; L. Colloca and Barsky, 2020; Kaptchuk et al., 2020). To measure and control for placebo analgesia, expectations can be measured with subjective rating scales (Cormier et al., 2013; Kaptchuk et al., 2020; Puhl et al., 2017).

The contribution of placebo effects induced by expectations to pain relief by SM was investigated in a few studies (Bialosky et al, 2008; Bialosky et al., 2014; Bishop et al., 2011b; Bishop et al., 2017). In healthy volunteers, it was reported that pain relief by SM is influenced by expectations, where negative expectations produce region-specific pain increases (Bialosky et al., 2008). In this study, however, SM-induced hypoalgesia was independent of positive expectations (Bialosky et al., 2008). In patients with LBP, it was also shown that SMT produces pain relief that cannot be attributed to expectations (Bialosky et al., 2014). In addition, it was shown that treating LBP with SM in patients that meet the clinical prediction rule of good prognosis is more important than patient's preference, and that the provider's preference is a better predictor of pain relief compared with patient's expectations (Bishop et al., 2011b; Bishop et al., 2017). Together, these results indicate that SM hypoalgesia and pain relief by SMT rely on specific mechanisms that are independent of expectations. This does not rule out the modulation of these effects by expectations or the influence of other non-specific effects that should also be measured and controlled for with appropriate placebo interventions.

\subsection{Placebo interventions for studies on spinal manipulation}

Every intervention induces non-specific effects related to the clinical or experimental context (Kaptchuk et al., 2020). Thus, a group receiving a placebo intervention is required to determine the specific therapeutic effects of an intervention. To achieve blinding, an appropriate placebo intervention must be structurally equivalent to (same context, positioning, duration and number of sessions) and indistinguishable from the studied intervention. In addition, the placebo intervention must not produce any therapeutic effect (inertness) (Hancock et al., 2006; Puhl et al., 2017). Currently, there is no consensus on what constitutes an appropriate placebo intervention for SM and SMT (Hancock et al., 2006). Developing an appropriate placebo remains challenging due to the lack of knowledge on 
what are the active components of SM (Hancock et al., 2006; Hawk et al., 2002; Koes, 2004; Puhl et al., 2017). Systematic reviews have reported that the placebo interventions used for SMT frequently lack at least one important element to be indistinguishable from SM (Puhl et al, 2017; Vernon et al., 2011). The concern regarding inadequate placebo interventions in spine pain research is not limited to SMT (Machado et al, 2008). A systematic review reported that only $20 \%$ of the trials on LBP used placebo interventions that were indistinguishable and equivalent to the active treatment, while blinding success was assessed in only $13 \%$ of the trials (Machado et al., 2008).

Inadequate blinding has been highlighted as one of the main weaknesses of research on manual therapies (Koes, 2004; Puhl et al, 2017; Vernon et al., 2011). As opposed to pharmacological research in which the patients and experimenters cannot distinguish active or placebo (inert) medication, single blinding remains challenging in SM research and double blinding is essentially impossible (Koes, 2004). Indeed, participants may not be aware of the intervention that they are receiving (real or placebo SM), but the force and cavitation associated with most SM requires that participants are naïve to SM to increase the odds of success ful blinding (Puhl et al., 2017). In addition, the experimenter is always aware of the intervention that is provided in the case of SM. To partially compensate for the lack of experimenter blinding, the placebo SM must be delivered in the most convincing way, which requires extensive practice (Hawk et al., 2002; Hawk et al., 1999; Koes, 2004; Vernon et al., 2011). Despite these limitations, high quality research on SM and SMT is not impossible and some approaches to reduce the impact of these limitations will now be discussed.

Instrument-assisted SM has been used in previous studies with the idea that the placebo intervention would be indistinguishable from SM (Hawk et al., 2002; Hawk et al., 1999). In these studies, the placebo intervention consisted in doing the same preparation (instructions, palpation of the spine, and instrument application with an associated sound), but no force was applied (Hawk et al., 2002; Hawk et al., 1999). This was effective in blinding participants (50\% in each group correctly guessed their group assignment). Yet, a major limitation is that the placebo intervention was not equivalent and that it might not be inert (Hawk et al., 2002; Hawk et al., 1999). Mechanically-assisted and manual SM do not have identical force-time profiles (C. J. Colloca et al., 2005; Herzog, 2010; Pickar and Bolton, 2012). Yet, mechanical instruments are commonly used by chiropractors as a clinical intervention (Huggins et al., 2012). These techniques offer the advantage of standardizing forces applied during SM, with a lesser degree of variability compared with manually-applied SM (Kawchuk et al, 2006). In the laboratory setting, further standardization of SM 
parameters can be reached by using linear motors, which mimic the force-time profiles measured during manually delivered SM. This allows determining the dose-physiological response characteristics of SM (Descarreaux et al., 2013). By adjusting the biomechanical parameters of SM, it may be possible to determine the therapeutic thresholds, as well as the sub-therapeutic doses that may constitute a placebo SM. Indeed, the biomechanical dosage parameters of SM to effectively induce analgesia are still unknown (Pasquier et al., 2019; Puhl et al., 2017). This remains to be explored and the validation of the appropriate placebo remains to be demonstrated.

Only a few studies examined the validity of placebo SM by assessing the degree of blinding (Chaibi et al, 2015; Vernon et al., 2012). To determine if blinding was success ful, participants were asked whether they had received the real/active treatment or the placebo (Chaibi et al., 2015; Vernon et al., 2012). In one of these studies, participants reported their treatment group correctly in $50 \%$ and $47 \%$ for the active and placebo interventions, respectively, indicating that blinding was successful (Vernon et al, 2012). In the placebo intervention, the joint preload and thrust phases were not performed and the maneuver consisted in a rapid motion through the drop action of the table's head-piece mechanism. The drop mechanism and the associated sound may be important factors that made blinding effective (Vernon et al, 2012). In the other study, the placebo intervention consisted in nonspecific contacts with lower force delivered on the gluteal and scapular regions instead of the spine, which did not produce cavitation (Chaibi et al., 2015). This placebo intervention was effective at blinding participants throughout 12 treatment sessions over three months. For each session, more than $80 \%$ reported that they had received the active treatment, irrespective of group allocation (Chaibi et al., 2015). Both studies seem to provide structurally equivalent and indistinguishable placebo interventions, even in patients with previous experience with SMT. Notwithstanding, it should be confirmed that the placebo interventions did not induce therapeutic effects (Chaibi et al., 2015; Vernon et al., 2012). Vernon et el. showed that the loads applied during the placebo intervention were lower compared with SM (10 to 50\%), but this does not ascertain the lack of a therapeutic effect, particularly considering that pain intensity reductions were no different between both groups (Vernon et al, 2012).

A unique study showed that true blinding is possible for SM (Kawchuk et al., 2009). In this experiment, SM was administered under short propofol/remifentanil anesthesia in the experimental group while the control group did not receive any intervention other than the anesthesia. In both groups, standardized visual and auditory cues were delivered before the 
participants recovered from anesthesia. Participants did not recall any memory from the anesthesia period, including the visual and auditory cues, indicating effective blinding (Kawchuk et al., 2009). Although the method is conceptually appealing, its applicability is limited and may be ethically questionable. In addition, the inertness of the anesthetics utilized must still be confirmed (Kawchuk et al., 2009). This may explain why this placebo intervention has not been used in subsequent studies.

Table 2 summarizes the placebo and control groups from studies presented in this review. In order to improve basic and clinical research on pain relief by SM, the quality of control and placebo interventions must be improved. This will further our understanding of the SM mechanisms and clinical effectiveness, by ruling out non-specific effects. In addition, more research on the dosage parameters of an effective SM is needed to determine what are the therapeutic or active components of SM, including the biomechanical loads and forces, the peripheral afferent and central processes as well as other variables.

\section{Future perspectives and conclusion}

Research on the mechanisms of SM has progressed significantly in recent years. Some of the mechanisms underlying treatment outcomes are becoming clearer and the advancement of pain research is contributing to this development. The new classification recently provided by the pain research community should allow a better understanding of chronic primary pain conditions, including those affecting the spine (Treede et al., 2019). The adoption of these changes by the spine pain research community should improve evidence on the use of SMT in the management of acute, subacute, and chronic NP and LBP.

Future basic research can contribute to improving the recommendations for the management of spine pain. Gaining a better understanding of the mechanisms by which SM can attenuate pain may help guiding clinical research by determining the specific mechanisms on which SM may act and in which conditions this may translate into clinical benefits. The use of appropriate, standardized placebo interventions and blinding strategies in both mechanistic and clinical trials is deemed essential to improving the quality of research.

The evidence presented in this review suggests that SM produces neurophysiological effects mainly via spinal cord mechanisms. These include segmental mechanisms of pain inhibition involving a reduction in temporal summation of pain. These mechanisms could 
partially explain some of the effects of SM observed locally and regionally. However, the reason why certain modalities seem to be more affected than others remains to be clarified. This could be due to SM influencing a specific group of nociceptive fibers. Modulation of Cfibers may influence the development of secondary hyperalgesia, which is characterized by increased sensitivity to mechanical but not thermal painful stimuli (Ali et al., 1996; Simone et al., 1989; Torebjork et al., 1992). Future research should explore potential anti-hyperalgesic effects of SM that are particularly relevant to chronic pain.

Some of the hypoalgesic effects cannot be explained by segmental mechanisms. In order to better understand these effects, measuring variables related to peripheral pain mechanisms should be considered (e.g., ROS and cytokines). Regarding supraspinal mechanisms, showing that brain activity changes after SM is not sufficient to conclude on the underlying mechanisms, so it remains to be determined how and whether SM may induce changes in brain activity, which in turn produce pain inhibition.

Recent experiments have provided insight into changes induced by SM in peripheral tissues that are most likely mediated by local growth factors and not by the nervous system (Conesa-Buendia et al., 2020; Lopez-Herradon et al, 2017). These effects provide a new avenue for investigating peripheral mechanisms involved in tissue damage and inflammation, likely influencing musculoskeletal pain. It has also been suggested that SM might regulate the activity of the sympathetic nervous system, which in turn could modulate inflammation (Gyer et al., 2019; Kovanur-Sampath et al., 2015). However, most mechanistic experiments have failed to identify clinically relevant changes induced by SMT (Honore et al., 2019). In order to close the gap between basic and clinical research, translational research is needed. Randomized controlled trials on the effectiveness of SMT on spine pain in which neurophysiological variables are measured are one possibility that could link experimental and clinical research findings (Clark et al., 2018). Further exploration of mechanistic trial designs will improve our understanding of the biological mechanisms underlying the efficacy (or physiological and clinical effects) of SM while optimizing the clinical management of spine pain with SMT and other conservative approaches (Karanicolas et al., 2009).

Besides the limitations related to the difficulties in translating evidence from basic science studies to the clinical realm, another important limitation comes from the quality of the placebo interventions and controls. The use of validated placebo interventions is not universal in SM research, which dramatically impacts the quality of studies. Therefore, the data from the studies presented need to be interpreted with caution. Designing an appropriate placebo for $\mathrm{SM}$ is challenging but is essential for future research on the mechanisms and

This article is protected by copyright. All rights reserved 
clinical effectiveness of SMT. Meanwhile, the available findings from animal studies provide support to a specific effect of SM, particularly influencing segmental mechanisms of pain inhibition (Duarte et al., 2019; Grayson et al., 2012; Onifer et al., 2015; Onifer et al., 2018). Additionally, human data suggests that SM hypoalgesia relies, at least partially, on specific mechanisms independent of expectations (Bialosky et al., 2008; Bialosky et al., 2014; Bishop et al., 2011b; Bishop et al., 2017). Validation studies have demonstrated that it is possible to design credible placebo interventions that are structurally equivalent to and indistinguishable from SM, even for multiple sessions in patients previously exposed to SM (Chaibi et al., 2015; Vernon et al., 2012). Nevertheless, a question that remains unanswered is whether these placebo interventions lack any therapeutic effects (Chaibi et al., 2015; Vernon et al., 2012). Indeed, these placebo interventions allowed successful blinding, but reported no significant group difference (Aspinall et al., 2019a; Honore et al., 2020). This was interpreted as a lack of therapeutic effect of SMT, but it could be argued that the placebo intervention may not be inert and may have masked therapeutic effects.

Research on placebo analgesia has shown that deceptive experiments (in which the participant receives the instruction that the placebo is in fact effective) achieve greater placebo effects compared with trials in which group allocation is uncertain (Kaptchuk et al, 2020; Vase et al., 2002). Open-label placebo experiments have shown that the placebo effect can be used to influence treatment outcomes effectively (Kaptchuk et al., 2020). In clinical practice, this could be attained by, for example, providing realistic but positive information about the prognosis (L. Colloca and Barsky, 2020), or by avoiding messages that could influence patients beliefs negatively, resulting in increased vigilance, worry, or frustration (L. Colloca and Barsky, 2020; Darlow et al., 2013).

The gaps identified in research on pain mechanisms of SM should guide future investigations. Although basic and clinical research on SMT provide some converging results, it remains a constant challenge to design basic studies that provide results that inform clinical research. Mechanistic trials in which basic research measures are implemented in clinical trials offer an interesting possibility to bridge this gap. Improving our understanding of how SM mediates pain relief through specific and non-specific mechanisms should translate into more homogenous recommendations on its use for specific patients, conditions, and pain states.

\section{Abbreviations}

This article is protected by copyright. All rights reserved 
ACP: American College of Physicians; CPGs: Clinical Practice Guidelines; IL-1 $\beta$ : Interleukin one beta; IL-10: Interleukin ten; LBP: Low back pain; NICE: National Institute for Health and Care Excellence; NP: Neck pain; PPTs: Pressure pain thresholds; SM: Spinal manipulation; SMT: Spinal manipulative therapy; ROS: Reactive oxygen species.

\section{Author contributions}

Each author contributed significantly to this work and has read and approved the final version of the manuscript. C.G-M. contributed to literature review, study selection and wrote the preliminary version of the manuscript. B.P. contributed to the literature review, M.D. contributed to manuscript editing, A.O contributed to manuscript editing and guidance in its design, M.P. contributed to the literature review, wrote the final version of the manuscript and obtained funding.

\section{Acknowledgements}

Figure 1 was created with BioRender.com.

\section{Conflicts of interest}

The authors report no financial or other relationships that may lead to any conflicts of interest. 


\section{References}

Abbadie, C., Lindia, J. A., Cumiskey, A. M., Peterson, L. B., Mudgett, J. S., Bayne, E. K., . . . Forrest, M. J. (2003). Impaired neuropathic pain responses in mice lacking the chemokine receptor CCR2. Proc Natl Acad Sci U S A, 100(13), 7947-7952. doi:10.1073/pnas.1331358100

Ali, Z., Meyer, R. A., \& Campbell, J. N. (1996). Secondary hyperalgesia to mechanical but not heat stimuli following a capsaic in injection in hairy skin. Pain, 68(2-3), 401-411. doi:10.1016/s0304-3959(96)03199-5

Almay, B. G. L., Johansson, F., Von Knorring, L., Le Greves, P., \& Terenius, L. (1988). Substance $\mathrm{P}$ in CSF of patients with chronic pain syndromes. Pain, 33(1), 3-9. doi:10.1016/0304-3959(88)90197-2

Alonso-Perez, J. L., Lopez-Lopez, A., La Touche, R., Lerma-Lara, S., Suarez, E., Rojas, J., . . . Fernandez-Carnero, J. (2017). Hypoalgesic effects of three different manual therapy techniques on cervical spine and psychological interaction: A randomized clinical trial. J Bodyw Mov Ther, 21(4), 798-803. doi:10.1016/j.jbmt.2016.12.005

Apkarian, A. V., Bushnell, M. C., Treede, R. D., \& Zubieta, J. K. (2005). Human brain mechanisms of pain perception and regulation in health and disease. Eur J Pain, 9(4), 463-484. doi:10.1016/j.ejpain.2004.11.001

Apkarian, A. V., Hashmi, J. A., \& Baliki, M. N. (2011). Pain and the brain: specificity and plasticity of the brain in clinical chronic pain. Pain, 152(3 Suppl), S49-64. doi:10.1016/j.pain.2010.11.010

Aspinall, S. L., Jacques, A., Leboeuf- Yde, C., Etherington, S. J., \& Walker, B. F. (2019a). No difference in pressure pain threshold and temporal summation after lumbar spinal manipulation compared to sham: A randomised controlled trial in adults with low back pain. Musculoskelet Sci Pract, 43, 18-25. doi:10.1016/j.msksp.2019.05.011

Aspinall, S. L., Leboeuf-Yde, C., Etherington, S. J., \& Walker, B. F. (2019b). Manipulationinduced hypoalgesia in musculoskeletal pain populations: a systematic critical review and meta-analysis. Chiropr Man Therap, 27, 7. doi:10.1186/s12998-018-0226-7

Baliki, M. N., Mansour, A. R., Baria, A. T., \& Apkarian, A. V. (2014). Functional reorganization of the default mode network across chronic pain conditions. PLoS One, 9(9), e106133. doi:10.1371/journal.pone.0106133

Beliveau, P. J. H., Wong, J. J., Sutton, D. A., Simon, N. B., Bussières, A. E., Mior, S. A., \& French, S. D. (2017). The chiropractic profession: a scoping review of utilization rates, 
reasons for seeking care, patient profiles, and care provided. Chiropr Man Therap, 25(1). doi:10.1186/s12998-017-0165-8

Benedetti, F., Arduino, C., \& Amanzio, M. (1999). Somatotopic activation of opioid systems by target-directed expectations of analgesia. J Neurosci, 19(9), 3639-3648. Retrieved from https://www.ncbi.nlm.nih. gov/pubmed/10212322

Bereznick, D. E., Ross, J. K., \& McGill, S. M. (2002). The frictional properties at the thoracic skin-fascia interface: implications in spine manipulation. Clin Biomech (Bristol, Avon), 17(4), 297-303. doi:10.1016/s0021-9290(02)00014-3

Bialosky, J. E., Beneciuk, J. M., Bishop, M. D., Coronado, R. A., Penza, C. W., Simon, C. B., \& George, S. Z. (2018). Unraveling the Mechanisms of Manual Therapy: Modeling an Approach. J Orthop Sports Phys Ther, 48(1), 8-18. doi:10.2519/jospt.2018.7476

Bialosky, J. E., Bishop, M. D., Price, D. D., Robinson, M. E., \& George, S. Z. (2009a). The mechanisms of manual therapy in the treatment of musculoskeletal pain: a comprehensive model. Man Ther, 14(5), 531-538. doi:10.1016/j.math.2008.09.001

Bialosky, J. E., Bishop, M. D., Robinson, M. E., Barabas, J. A., \& George, S. Z. (2008). The influence of expectation on spinal manipulation induced hypoalgesia: an experimental study in normal subjects. BMC Musculoskelet Disord, 9, 19. doi:10.1186/1471-2474-919

Bialosky, J. E., Bishop, M. D., Robinson, M. E., Zeppieri, G., Jr., \& George, S. Z. (2009b). Spinal manipulative therapy has an immediate effect on thermal pain sensitivity in people with low back pain: a randomized controlled trial. Phys Ther, 89(12), $1292-$ 1303. doi:10.2522/ptj.20090058

Bialosky, J. E., George, S. Z., Horn, M. E., Price, D. D., Staud, R., \& Robinson, M. E. (2014). Spinal manipulative therapy-specific changes in pain sensitivity in individuals with low back pain (NCT01168999). $J$ Pain, 15(2), 136-148. doi:10.1016/j.jpain.2013.10.005

Bishop, M. D., Beneciuk, J. M., \& George, S. Z. (2011a). Immediate reduction in temporal sensory summation after thoracic spinal manipulation. Spine J, 11(5), 440-446. doi:10.1016/j.spinee.2011.03.001

Bishop, M. D., Bialosky, J. E., \& Cleland, J. A. (2011b). Patient expectations of benefit from common interventions for low back pain and effects on outcome: secondary analysis of a clinical trial of manual therapy interventions. J Man Manip Ther, 19(1), 20-25. doi:10.1179/106698110X12804993426929

Bishop, M. D., Bialosky, J. E., Penza, C. W., Beneciuk, J. M., \& Alappattu, M. J. (2017). The

This article is protected by copyright. All rights reserved 
influence of clinical equipoise and patient preferences on outcomes of conservative manual interventions for spinal pain: an experimental study. $J$ Pain Res, 10, 965-972. doi:10.2147/JPR.S130931

Borghouts, J. A., Koes, B. W., \& Bouter, L. M. (1998). The clinical course and prognostic factors of non-specific neck pain: a systematic review. Pain, 77(1), 1-13. doi:10.1016/s0304-3959(98)00058-x

Brown, R. A. (2016). Spinal Health: The Backbone of Chiropractic's Identity. J Chiropr Humanit, 23(1), 22-28. doi:10.1016/j.echu.2016.07.002

Bussieres, A. E., Stewart, G., Al-Zoubi, F., Decina, P., Descarreaux, M., Haskett, D., . . . Ornelas, J. (2018). Spinal Manipulative Therapy and Other Conservative Treatments for Low Back Pain: A Guideline From the Canadian Chiropractic Guideline Initiative. $J$ Manipulative Physiol Ther, 41(4), 265-293. doi:10.1016/j.jmpt.2017.12.004

Cadden, S. W., Villanueva, L., Chitour, D., \& Le Bars, D. (1983). Depression of activities of dorsal horn convergent neurones by propriospinal mechanisms triggered by noxious inputs; comparison with diffuse noxious inhibitory controls (DNIC). Brain Res, 275(1), 1-11. doi:10.1016/0006-8993(83)90412-2

Cao, Y. Q., Mantyh, P. W., Carlson, E. J., Gillespie, A. M., Epstein, C. J., \& Basbaum, A. I. (1998). Primary afferent tachykinins are required to experience moderate to intense pain. Nature, 392(6674), 390-394. doi:10.1038/32897

Casanova-Mendez, A., Oliva-Pascual-Vaca, A., Rodriguez-Blanco, C., Heredia-Rizo, A. M., Gogorza-Arroitaonandia, K., \& Almazan-Campos, G. (2014). Comparative short-term effects of two thoracic spinal manipulation techniques in subjects with chronic mechanical neck pain: a randomized controlled trial. Man Ther, 19(4), 331-337. doi:10.1016/j.math.2014.03.002

Chaibi, A., Saltyte Benth, J., \& Bjorn Russell, M. (2015). Validation of Placebo in a Manual Therapy Randomized Controlled Trial. Sci Rep, 5, 11774. doi:10.1038/srep11774

Clark, B. C., Russ, D. W., Nakazawa, M., France, C. R., Walkowski, S., Law, T. D., .. . Thomas, J. S. (2018). A randomized control trial to determine the effectiveness and physiological effects of spinal manipulation and spinal mobilization compared to each other and a sham condition in patients with chronic low back pain: Study protocol for The RELIEF Study. Contemp Clin Trials, 70, 41-52. doi:10.1016/j.cct.2018.05.012

Colloca, C. J., Keller, T. S., Black, P., Normand, M. C., Harrison, D. E., \& Harrison, D. D. (2005). Comparison of mechanical force of manually assisted chiropractic adjusting

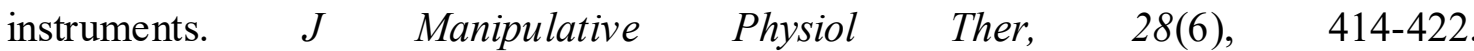


doi:10.1016/j.jmpt.2005.06.004

Colloca, L., \& Barsky, A. J. (2020). Placebo and Nocebo Effects. N Engl J Med, 382(6), 554561. doi:10.1056/NEJMra1907805

Conesa-Buendia, F. M., Mediero, A., Fujikawa, R., Esbrit, P., Mulero, F., MahilloFernandez, I., \& Mues, A. O. (2020). Beneficial effects of manually assisted chiropractic adjusting instrument in a rabbit model of osteoarthritis. Sci Rep, 10(1), 13237. doi:10.1038/s41598-020-70219-3

Cormier, S., Piche, M., \& Rainville, P. (2013). Expectations modulate heterotopic noxious counter-stimulation analgesia. J Pain, 14(2), 114-125. doi:10.1016/j.jpain.2012.10.006

Coronado, R. A., Gay, C. W., Bialosky, J. E., Carnaby, G. D., Bishop, M. D., \& George, S. Z. (2012). Changes in pain sensitivity following spinal manipulation: a systematic review and meta-analysis. $J$ Electromyogr Kinesiol, 22(5), 752-767. doi:10.1016/j.jelekin.2011.12.013

Cote, P., Wong, J. J., Sutton, D., Shearer, H. M., Mior, S., Randhawa, K., . . . Salhany, R. (2016). Management of neck pain and associated disorders: A clinical practice guideline from the Ontario Protocol for Traffic Injury Management (OPTIMa) Collaboration. Eur Spine J, 25(7), 2000-2022. doi:10.1007/s00586-016-4467-7

Darlow, B., Dowell, A., Baxter, G. D., Mathieson, F., Perry, M., \& Dean, S. (2013). The enduring impact of what clinicians say to people with low back pain. Ann Fam Med, 11(6), 527-534. doi:10.1370/afm. 1518

de Camargo, V. M., Alburquerque-Sendin, F., Berzin, F., Stefanelli, V. C., de Souza, D. P., \& Fernandez-de-las-Penas, C. (2011). Immediate effects on electromyographic activity and pressure pain thresholds after a cervical manipulation in mechanical neck pain: a randomized controlled trial. J Manipulative Physiol Ther, 34(4), 211-220. doi:10.1016/j.jmpt.2011.02.002

Descarreaux, M., Nougarou, F., \& Dugas, C. (2013). Standardization of spinal manipulation therapy in humans: development of a novel device designed to measure dose-response. J Manipulative Physiol Ther, 36(2), 78-83. doi:10.1016/j.jmpt.2012.12.007

Dickenson, A. H. (1995). Central acute pain mechanisms. Ann Med, 27(2), 223-227. doi:10.3109/07853899509031963

Dorron, S. L., Losco, B. E., Drummond, P. D., \& Walker, B. F. (2016). Effect of lumbar spinal manipulation on local and remote pressure pain threshold and pinprick sensitivity in asymptomatic individuals: a randomised trial. Chiropr Man Therap, 24, 47. doi:10.1186/s12998-016-0128-5

This article is protected by copyright. All rights reserved 
Duarte, F. C. K., Kolberg, C., Riffel, A. P. K., Souza, J. A., Bello-Klein, A., \& Partata, W. A. (2019). Spinal Manipulation Therapy Improves Tactile Allodynia and Peripheral Nerve Functionality and Modulates Blood Oxidative Stress Markers in Rats Exposed to KneeJoint Immobilization. $J$ Manipulative Physiol Ther, 42(6), 385-398. doi:10.1016/j.jmpt.2018.11.023

Eippert, F., Bingel, U., Schoell, E. D., Yacubian, J., Klinger, R., Lorenz, J., \& Buchel, C. (2009). Activation of the opioidergic descending pain control system underlies placebo analgesia. Neuron, 63(4), 533-543. doi:10.1016/j.neuron.2009.07.014

Ellingsen, D. M., Napadow, V., Protsenko, E., Mawla, I., Kowalski, M. H., Swensen, D., . . . Loggia, M. L. (2018). Brain Mechanisms of Anticipated Painful Movements and Their Modulation by Manual Therapy in Chronic Low Back Pain. J Pain, 19(11), 1352-1365. doi:10.1016/j.jpain.2018.05.012

Fernandez-Carnero, J., Fernandez-de-las-Penas, C., \& Cleland, J. A. (2008). Immediate hypoalgesic and motor effects after a single cervical spine manipulation in subjects with lateral epicondylalgia. J Manipulative Physiol Ther, 31(9), 675-681. doi:10.1016/j.jmpt.2008.10.005

Fernandez-de-las-Penas, C., Perez-de-Heredia, M., Brea-Rivero, M., \& Miangolarra-Page, J. C. (2007). Immediate effects on pressure pain threshold following a single cervical spine manipulation in healthy subjects. J Orthop Sports Phys Ther, 37(6), 325-329. doi:10.2519/jospt.2007.2542

Foster, N. E., Anema, J. R., Cherkin, D., Chou, R., Cohen, S. P., Gross, D. P., . . . Lancet Low Back Pain Series Working, G. (2018). Prevention and treatment of low back pain: evidence, challenges, and promising directions. Lancet, 391(10137), 2368-2383. doi:10.1016/S0140-6736(18)30489-6

Fryer, G., Carub, J., \& McIver, S. (2004). The effect of manipulation and mobilisation on pressure pain thresholds in the thoracic spine. Journal of Osteopathic Medicine, 7(1), 814.

Funabashi, M., Nougarou, F., Descarreaux, M., Prasad, N., \& Kawchuk, G. N. (2017). Spinal Tissue Loading Created by Different Methods of Spinal Manipulative Therapy $\begin{array}{lllll}\text { Application. } \quad \text { Spine } \quad \text { (Phila } \quad P a & \text { 1976), }\end{array}$ doi:10.1097/BRS.0000000000002096

Gay, C. W., Robinson, M. E., George, S. Z., Perlstein, W. M., \& Bishop, M. D. (2014). Immediate changes after manual therapy in resting-state functional connectivity as measured by functional magnetic resonance imaging in participants with induced low

This article is protected by copyright. All rights reserved 
back pain. J Manipulative Physiol Ther, 37(9), 614-627. doi:10.1016/j.jmpt.2014.09.001

George, S. Z., Bishop, M. D., Bialosky, J. E., Zeppieri, G., Jr., \& Robinson, M. E. (2006). Immediate effects of spinal manipulation on thermal pain sensitivity: an experimental study. BMC Musculoskelet Disord, 7, 68. doi:10.1186/1471-2474-7-68

Grayson, J. E., Barton, T., Cabot, P. J., \& Souvlis, T. (2012). Spinal manual therapy produces rapid onset analgesia in a rodent model. Man Ther, 17(4), 292-297. doi:10.1016/j.math.2012.02.004

Gyer, G., Michael, J., Inklebarger, J., \& Tedla, J. S. (2019). Spinal manipulation therapy: Is it all about the brain? A current review of the neurophysiological effects of manipulation. J Integr Med, 17(5), 328-337. doi:10.1016/j.joim.2019.05.004

Hackam, D. G., \& Redelmeier, D. A. (2006). Translation of research evidence from animals to humans. JAMA, 296(14), 1731-1732. doi:10.1001/jama.296.14.1731

Hackel, D., Brack, A., \& Rittner, H. L. (2010). Chapter 19 - Leukocytes as Mediators of Pain and Analgesia. In B. G. Arnason (Ed.), NeuroImmune Biology (Vol. 9, pp. 237-250): Elsevier.

Hancock, M. J., Maher, C. G., Latimer, J., \& McAuley, J. H. (2006). Selecting an appropriate placebo for a trial of spinal manipulative therapy. Aust J Physiother, 52(2), 135-138. doi:10.1016/s0004-9514(06)70049-6

Hannibal, K. E., \& Bishop, M. D. (2014). Chronic stress, cortisol dysfunction, and pain: a psychoneuroendocrine rationale for stress management in pain rehabilitation. Phys Ther, 94(12), 1816-1825. doi:10.2522/ptj.20130597

Hartvigsen, J., Hancock, M. J., Kongsted, A., Louw, Q., Ferreira, M. L., Genevay, S., .. . Lancet Low Back Pain Series Working, G. (2018). What low back pain is and why we need to pay attention. Lancet, 391(10137), 2356-2367. doi:10.1016/S01406736(18)30480-X

Hawk, C., Long, C. R., Reiter, R., Davis, C. S., Cambron, J. A., \& Evans, R. (2002). Issues in planning a placebo-controlled trial of manual methods: results of a pilot study. $J$ Altern Complement Med, 8(1), 21-32. doi:10.1089/107555302753507159

Hawk, C., Phongphua, C., Bleecker, J., Swank, L., Lopez, D., \& Rubley, T. (1999). Preliminary study of the reliability of assessment procedures for indications for chiropractic adjustments of the lumbar spine. J Manipulative Physiol Ther, 22(6), 382389. doi:10.1016/s0161-4754(99)70083-7

Hench, P. S., Kendall, E. C., Slocumb, C. H., \& Polley, H. F. (1950). Effects of cortisone

This article is protected by copyright. All rights reserved 
acetate and pituitary ACTH on rheumatoid arthritis, rheumatic fever and certain other conditions. Arch Intern Med (Chic), 85(4), 545-666. doi:10.1001/archinte.1950.00230100002001

Henderson, C. N. (2012). The basis for spinal manipulation: chiropractic perspective of indications and theory. $J$ Electromyogr Kinesiol, 22(5), 632-642. doi:10.1016/j.jelekin.2012.03.008

Herzog, W. (2010). The biomechanics of spinal manipulation. J Bodyw Mov Ther, 14(3), 280-286. doi:10.1016/j.jbmt.2010.03.004

Herzog, W., Kats, M., \& Symons, B. (2001). The effective forces transmitted by high-speed, low-amplitude thoracic manipulation. Spine (Phila Pa 1976), 26(19), 2105-2110; discussion 2110-2101. doi:10.1097/00007632-200110010-00012

Honore, M., Leboeuf-Yde, C., \& Gagey, O. (2018). The regional effect of spinal manipulation on the pressure pain threshold in asymptomatic subjects: a systematic literature review. Chiropr Man Therap, 26, 11. doi:10.1186/s12998-018-0181-3

Honore, M., Leboeuf-Yde, C., Gagey, O., \& Wedderkopp, N. (2019). How big is the effect of spinal manipulation on the pressure pain threshold and for how long does it last? secondary analysis of data from a systematic review. Chiropr Man Therap, 27, 22. doi:10.1186/s12998-019-0240-4

Honore, M., Picchiottino, M., Wedderkopp, N., Leboeuf-Yde, C., \& Gagey, O. (2020). What is the effect of spinal manipulation on the pressure pain threshold in young, asymptomatic subjects? A randomized placebo-controlled trial, with a cross-over design. Chiropr Man Therap, 28(1), 6. doi:10.1186/s12998-020-0296-1

Huggins, T., Boras, A. L., Gleberzon, B. J., Popescu, M., \& Bahry, L. A. (2012). Clinical effectiveness of the activator adjusting instrument in the management of musculoskeletal disorders: a systematic review of the literature. J Can Chiropr Assoc, 56(1), 49-57. Retrieved from https:/www.ncbi.nlm.nih.gov/pubmed/22457541

James, S. L., Abate, D., Abate, K. H., Abay, S. M., Abbafati, C., Abbasi, N., . . Abdelalim, A. (2018). Global, regional, and national incidence, prevalence, and years lived with disability for 354 diseases and injuries for 195 countries and territories, 1990-2017: a systematic analysis for the Global Burden of Disease Study 2017. The Lancet, 392(10159), 1789-1858.

Ji, R. R., Nackley, A., Huh, Y., Terrando, N., \& Maixner, W. (2018). Neuroinflammation and Central Sensitization in Chronic and Widespread Pain. Anesthesiology, 129(2), 343366. doi:10.1097/ALN.0000000000002130

This article is protected by copyright. All rights reserved 
Jordon, M. K., Beattie, P. F., D'Urso, S., \& Scriven, S. (2017). Spinal manipulation does not affect pressure pain thresholds in the absence of neuromodulators: a randomized controlled trial. J Man Manip Ther, 25(4), 172-181. doi:10.1080/10669817.2016.1230352

Kaptchuk, T. J., Hemond, C. C., \& Miller, F. G. (2020). Placebos in chronic pain: evidence, theory, ethics, and use in clinical practice. BMJ, 370, m1668. doi:10.1136/bmj.ml668

Karanicolas, P. J., Montori, V. M., Devereaux, P. J., Schunemann, H., \& Guyatt, G. H. (2009). A new 'mechanistic-practical" framework for designing and interpreting randomized trials. J Clin Epidemiol, 62(5), 479-484. doi:10.1016/j.jclinepi.2008.02.009

Kawasaki, Y., Zhang, L., Cheng, J. K., \& Ji, R. R. (2008). Cytokine mechanisms of central sensitization: distinct and overlapping role of interleukin-1beta, interleukin-6, and tumor necrosis factor-alpha in regulating synaptic and neuronal activity in the superficial spinal cord. J Neurosci, 28(20), 5189-5194. doi:10.1523/JNEUROSCI.333807.2008

Kawchuk, G. N., Haugen, R., \& Fritz, J. (2009). A true blind for subjects who receive spinal manipulation therapy. Arch Phys Med Rehabil, 90(2), 366-368. doi:10.1016/j.apmr.2008.08.213

Kawchuk, G. N., Prasad, N. G., McLeod, R. C., Liddle, T., Li, T., \& Zhu, Q. (2006). Variability of force magnitude and force duration in manual and instrument-based manipulation techniques. J Manipulative Physiol Ther, 29(8), 611-618. doi:10.1016/j.jmpt.2006.08.013

Kim, D., You, B., Jo, E. K., Han, S. K., Simon, M. I., \& Lee, S. J. (2010). NADPH oxidase 2derived reactive oxygen species in spinal cord microglia contribute to peripheral nerve injury-induced neuropathic pain. Proc Natl Acad Sci U S A, 107(33), 14851-14856. doi:10.1073/pnas.1009926107

Kjaer, P., Kongsted, A., Hartvigsen, J., Isenberg-Jorgensen, A., Schiottz-Christensen, B., Soborg, B., . . . Povlsen, T. M. (2017). National clinical guidelines for non-surgical treatment of patients with recent onset neck pain or cervical radiculopathy. Eur Spine J, 26(9), 2242-2257. doi:10.1007/s00586-017-5121-8

Koes, B. W. (2004). How to evaluate manual therapy: value and pitfalls of randomized clinical trials. Man Ther, 9(4), 183-184. doi:10.1016/j.math.2004.04.002

Kolberg, C., Horst, A., Moraes, M. S., Duarte, F. C., Riffel, A. P., Scheid, T., . . Partata, W. A. (2015). Peripheral oxidative stress blood markers in patients with chronic back or neck pain treated with high-velocity, low-amplitude manipulation. J Manipulative

This article is protected by copyright. All rights reserved 
Physiol Ther, 38(2), 119-129. doi:10.1016/j.jmpt.2014.11.003

Kovanur-Sampath, K., Botnmark, E., Mani, R., Cotter, J. D., Katare, R., Munasinghe, P. E., \& Tumilty, S. (2017a). Neuroendocrine Response Following a Thoracic Spinal Manipulation in Healthy Men. J Orthop Sports Phys Ther, 47(9), 617-627. doi:10.2519/jospt.2017.7348

Kovanur-Sampath, K., Mani, R., Cotter, J., Gisselman, A. S., \& Tumilty, S. (2017b). Changes in biochemical markers following spinal manipulation-a systematic review and meta-analysis. Musculoskelet Sci Pract, 29, 120-131. doi:10.1016/j.msksp.2017.04.004

Kovanur-Sampath, K., Mani, R., Cotter, J. D., \& Tumilty, S. (2015). Measureable changes in the neuro-endocrinal mechanism following spinal manipulation. Med Hypotheses, 85(6), 819-824. doi:10.1016/j.mehy.2015.10.003

Laframboise, M. A., Vernon, H., \& Srbely, J. (2016). Effect of two consecutive spinal manipulations in a single session on myofascial pain pressure sensitivity: a randomized controlled trial. J Can Chiropr Assoc, 60(2), 137-145. Retrieved from https://www.ncbi.nlm.nih.gov/pubmed/27385833

Lee, I., Kim, H. K., K im, J. H., Chung, K., \& Chung, J. M. (2007). The role of reactive oxygen species in capsaicin-induced mechanical hyperalgesia and in the activities of dorsal horn neurons. Pain, 133(1-3), 9-17. doi:10.1016/j.pain.2007.01.035

Lohman, E. B., Pacheco, G. R., Gharibvand, L., Daher, N., Devore, K., Bains, G., . . Berk, L. S. (2019). The immediate effects of cervical spine manipulation on pain and biochemical markers in females with acute non-specific mechanical neck pain: a randomized clinical trial. J Man Manip Ther, 27(4), 186-196. doi:10.1080/10669817.2018.1553696

Lopez-Herradon, A., Fujikawa, R., Gomez-Marin, M., Stedile-Lovatel, J. P., Mulero, F., Ardura, J. A., . . . Ortega-de Mues, A. (2017). Impact of Chiropractic Manipulation on Bone and Skeletal Muscle of Ovariectomized Rats. Calcif Tissue Int, 101(5), 519-529. doi:10.1007/s00223-017-0304-1

Machado, L. A., Kamper, S. J., Herbert, R. D., Maher, C. G., \& McAuley, J. H. (2008). Imperfect placebos are common in low back pain trials: a systematic review of the literature. Eur Spine J, 17(7), 889-904. doi:10.1007/s00586-008-0664-3

Machado, L. A., Kamper, S. J., Herbert, R. D., Maher, C. G., \& McAuley, J. H. (2009). Analgesic effects of treatments for non-specific low back pain: a meta-analysis of placebo-controlled randomized trials. Rheumatology (Oxford), 48(5), 520-527.

This article is protected by copyright. All rights reserved 
doi:10.1093/rheumatology/ken470

Magerl, W., Fuchs, P. N., Meyer, R. A., \& Treede, R. D. (2001). Roles of capsaicininsensitive nociceptors in cutaneous pain and secondary hyperalgesia. Brain, 124(Pt 9), 1754-1764. doi:10.1093/brain/124.9.1754

Marchand, F., Perretti, M., \& McMahon, S. B. (2005). Role of the immune system in chronic pain. Nat Rev Neurosci, 6(7), 521-532. doi:10.1038/nrn1700

Martinez-Segura, R., De-la-Llave-Rincon, A. I., Ortega-Santiago, R., Cleland, J. A., \& Fernandez-de-Las-Penas, C. (2012). Immediate changes in widespread pressure pain sensitivity, neck pain, and cervical range of motion after cervical or thoracic thrust manipulation in patients with bilateral chronic mechanical neck pain: a randomized clinical trial. J Orthop Sports Phys Ther, 42(9), 806-814. doi:10.2519/jospt.2012.4151

Mason, J. W., Hartley, L. H., Kotchen, T. A., Mougey, E. H., Ricketts, P. T., \& Jones, L. G. (1973). Plasma cortisol and norepinephrine responses in anticipation of muscular exercise. Psychosom Med, 35(5), 406-414. doi:10.1097/00006842-197309000-00004

Mendell, L. M., \& Wall, P. D. (1965). Responses of Single Dorsal Cord Cells to Peripheral Cutaneous Unmyelinated Fibres. Nature, 206, 97-99. doi:10.1038/206097a0

Menke, J. M. (2014). Do manual therapies help low back pain? A comparative effectiveness $\begin{array}{lllll}\text { meta-analysis. Spine } \quad \text { (Phila } & \text { Pa } & \text { 1976), } & \text { 39(7), } & \text { E463-472. }\end{array}$ doi:10.1097/BRS.0000000000000230

Meyer, A. L., Amorim, M. A., Schubert, M., Schweinhardt, P., \& Leboeuf-Yde, C. (2019). Unravelling functional neurology: does spinal manipulation have an effect on the brain? - a systematic literature review. Chiropr Man Therap, 27, 60. doi:10.1186/s12998-0190265-8

Millan, M., Leboeuf-Yde, C., Budgell, B., \& Amorim, M. A. (2012). The effect of spinal manipulative therapy on experimentally induced pain: a systematic literature review. Chiropr Man Therap, 20(1), 26. doi:10.1186/2045-709X-20-26

Millan, M. J. (2002). Descending control of pain. Prog Neurobiol, 66(6), 355-474. doi:10.1016/s0301-0082(02)00009-6

Mohammadian, P., Gonsalves, A., Tsai, C., Hummel, T., \& Carpenter, T. (2004). Areas of Capsaicin-Induced Secondary Hyperalgesia and Allodynia Are Reduced by a Single Chiropractic Adjustment: A Preliminary Study. J Manipulative Physiol Ther, 27(6), 381-387. doi:10.1016/j.jmpt.2004.05.002

Molina-Ortega, F., Lomas-Vega, R., Hita-Contreras, F., Plaza Manzano, G., Achalandabaso, A., Ramos-Morcillo, A. J., \& Martinez-Amat, A. (2014). Immediate effects of spinal

This article is protected by copyright. All rights reserved 
manipulation on nitric oxide, substance P and pain perception. Man Ther, 19(5), 411417. doi:10.1016/j.math.2014.02.007

Murphy, D. R., Justice, B. D., Paskowski, I. C., Perle, S. M., \& Schneider, M. J. (2011). The establishment of a primary spine care practitioner and its benefits to health care reform in the United States. Chiropr Man Therap, 19(1), 17. doi:10.1186/2045-709X-19-17

Nakatsuka, T., Chen, M., Takeda, D., King, C., Ling, J., Xing, H., . . . Gu, J. G. (2005). Substance P-driven feed-forward inhibitory activity in the mammalian spinal cord. Mol Pain, 1, 20. doi:10.1186/1744-8069-1-20

Nicholas, M., Vlaeyen, J. W. S., Rief, W., Barke, A., Aziz, Q., Benoliel, R., . . Pain, I. T. f. t. C. o. C. (2019). The IASP classification of chronic pain for ICD-11: chronic primary pain. Pain, 160(1), 28-37. doi:10.1097/j.pain.0000000000001390

Nim, C. G., Kawchuk, G. N., Schiottz-Christensen, B., \& O'Neill, S. (2020). The effect on clinical outcomes when targeting spinal manipulation at stiffness or pain sensitivity: a randomized trial. Sci Rep, 10(1), 14615. doi:10.1038/s41598-020-71557-y

Nougarou, F., Dugas, C., Deslauriers, C., Page, I., \& Descarreaux, M. (2013). Physiological responses to spinal manipulation therapy: investigation of the relationship between electromyographic responses and peak force. J Manipulative Physiol Ther, 36(9), 557563. doi:10.1016/j.jmpt.2013.08.006

Onifer, S. M., Reed, W. R., Sozio, R. S., \& Long, C. R. (2015). Antinociceptive Effects of Spinal Manipulative Therapy on Nociceptive Behavior of Adult Rats during the Formalin Test. Evid Based Complement Alternat Med, 2015, 520454. doi:10.1155/2015/520454

Onifer, S. M., Sozio, R. S., DiCarlo, D. M., Li, Q., Donahue, R. R., Taylor, B. K., \& Long, C. R. (2018). Spinal manipulative therapy reduces peripheral neuropathic pain in the rat. Neuroreport, 29(3), 191-196. doi:10.1097/WNR.0000000000000949

Pasquier, M., Daneau, C., Marchand, A. A., Lardon, A., \& Descarreaux, M. (2019). Spinal manipulation frequency and dosage effects on clinical and physiological outcomes: a scoping review. Chiropr Man Therap, 27, 23. doi:10.1186/s12998-019-0244-0

Pickar, J. G., \& Bolton, P. S. (2012). Spinal manipulative therapy and somatosensory activation. J Electromyogr Kinesiol, 22(5), 785-794. doi:10.1016/j.jelek in.2012.01.015

Plaza-Manzano, G., Molina-Ortega, F., Lomas-Vega, R., Martinez-Amat, A., Achalandabaso, A., \& Hita-Contreras, F. (2014). Changes in biochemical markers of pain perception and stress response after spinal manipulation. J Orthop Sports Phys Ther, 44(4), 231239. doi:10.2519/jospt.2014.4996

This article is protected by copyright. All rights reserved 
Price, D. D. (1972). Characteristics of second pain and flexion reflexes indicative of prolonged central summation. Exp Neurol, 37(2), 371-387. doi:10.1016/00144886(72)90081-7

Price, D. D., Hu, J. W., Dubner, R., \& Gracely, R. H. (1977). Peripheral suppression of first pain and central summation of second pain evoked by noxious heat pulses. Pain, 3(1), 57-68. doi:10.1016/0304-3959(77)90035-5

Puhl, A. A., Reinhart, C. J., Doan, J. B., \& Vernon, H. (2017). The quality of placebos used in randomized, controlled trials of lumbar and pelvic joint thrust manipulation-a systematic review. Spine J, 17(3), 445-456. doi:10.1016/j.spinee.2016.11.003

Puhl, A. A., Reinhart, C. J., Rok, E. R., \& Injeyan, H. S. (2011). An examination of the observed placebo effect associated with the treatment of low back pain - a systematic review. Pain Res Manag, 16(1), 45-52. doi:10.1155/2011/625315

Qaseem, A., Wilt, T. J., McLean, R. M., \& Forciea, M. A. (2017). Noninvasive Treatments for Acute, Subacute, and Chronic Low Back Pain: A Clinical Practice Guideline From the American College of Physicians. Ann Intern Med, 166(7), 514-530. doi:10.7326/M16-2367

Randoll, C., Gagnon-Normandin, V., Tessier, J., Bois, S., Rustamov, N., O'Shaughnessy, J., . . . Piche, M. (2017). The mechanism of back pain relief by spinal manipulation relies on decreased temporal summation of pain. Neuroscience, 349, 220-228. doi:10.1016/j.neuroscience.2017.03.006

Reed, W. R., Cao, D. Y., Long, C. R., Kawchuk, G. N., \& Pickar, J. G. (2013). Relationship between Biomechanical Characteristics of Spinal Manipulation and Neural Responses in an Animal Model: Effect of Linear Control of Thrust Displacement versus Force, Thrust Amplitude, Thrust Duration, and Thrust Rate. Evid Based Complement Alternat Med, 2013, 492039. doi:10.1155/2013/492039

Reed, W. R., Long, C. R., Kawchuk, G. N., \& Pickar, J. G. (2014). Neural responses to the mechanical parameters of a high-velocity, low-amplitude spinal manipulation: effect of preload parameters. J Manipulative Physiol Ther, 37(2), 68-78. doi:10.1016/j.jmpt.2013.12.004

Reed, W. R., Long, C. R., Kawchuk, G. N., \& Pickar, J. G. (2015). Neural responses to the mechanical characteristics of high velocity, low amplitude spinal manipulation: Effect of specific contact site. Man Ther, 20(6), 797-804. doi:10.1016/j.math.2015.03.008

Reed, W. R., \& Pickar, J. G. (2015). Paraspinal Muscle Spindle Response to Intervertebral Fixation and Segmental Thrust Level During Spinal Manipulation in an Animal Model. 
Spine (Phila Pa 1976), 40(13), E752-759. doi:10.1097/BRS.0000000000000915

Ross, J. K., Bereznick, D. E., \& McGill, S. M. (2004). Determining cavitation location during lumbar and thoracic spinal manipulation: is spinal manipulation accurate and specific? Spine (Phila Pa 1976), 29(13), 1452-1457. doi:10.1097/01.brs.0000129024.95630.57

Roussel, N. A., Nijs, J., Meeus, M., Mylius, V., Fayt, C., \& Oostendorp, R. (2013). Central sensitization and altered central pain processing in chronic low back pain: fact or myth? Clin J Pain, 29(7), 625-638. doi:10.1097/AJP.0b013e31826f9a71

Roy, R. A., Boucher, J. P., \& Comtois, A. S. (2010). Inflammatory response following a short-term course of chiropractic treatment in subjects with and without chronic low back pain. J Chiropr Med, 9(3), 107-114. doi:10.1016/j.jcm.2010.06.002

Russell, I. J., Orr, M. D., Littman, B., Vipraio, G. A., Alboukrek, D., Michalek, J. E., . . . MacKillip, F. (1994). Elevated cerebrospinal fluid levels of substance $P$ in patients with the fibromyalgia syndrome. Arthritis Rheum, 37(11), 1593-1601. doi:10.1002/art.1780371106

Saldanha, C., Tougas, G., \& Grace, E. (1986). Evidence for anti-inflammatory effect of normal circulating plasma cortisol. Clin Exp Rheumatol, 4(4), 365-366. Retrieved from https:/www.ncbi.nlm.nih.gov/pubmed/3791721

Salom-Moreno, J., Ortega-Santiago, R., Cleland, J. A., Palacios-Cena, M., TruyolsDominguez, S., \& Fernandez-de-las-Penas, C. (2014). Immediate changes in neck pain intensity and widespread pressure pain sensitivity in patients with bilateral chronic mechanical neck pain: a randomized controlled trial of thoracic thrust manipulation vs non-thrust mobilization. $J$ Manipulative Physiol Ther, 37(5), 312-319. doi:10.1016/j.jmpt.2014.03.003

Savva, C., Giakas, G., \& Efstathiou, M. (2014). The role of the descending inhibitory pain mechanism in musculoskeletal pain following high-velocity, low amplitude thrust manipulation: a review of the literature. J Back Musculoskelet Rehabil, 27(4), 377-382. doi:10.3233/BMR-140472

Scholten-Peeters, G. G., Thoomes, E., Konings, S., Beijer, M., Verkerk, K., Koes, B. W., \& Verhagen, A. P. (2013). Is manipulative therapy more effective than sham manipulation in adults : a systematic review and meta-analysis. Chiropr Man Therap, 21(1), 34. doi:10.1186/2045-709X-21-34

Schwartz, E. S., Lee, I., Chung, K., \& Chung, J. M. (2008). Oxidative stress in the spinal cord is an important contributor in capsaicin-induced mechanical secondary hyperalgesia in mice. Pain, 138(3), 514-524.

This article is protected by copyright. All rights reserved 
Simone, D. A., Baumann, T. K., \& LaMotte, R. H. (1989). Dose-dependent pain and mechanical hyperalgesia in humans after intradermal injection of capsaicin. Pain, 38(1), 99-107. doi:10.1016/0304-3959(89)90079-1

Sommer, C., \& Kress, M. (2004). Recent findings on how proinflammatory cytokines cause pain: peripheral mechanisms in inflammatory and neuropathic hyperalgesia. Neurosci Lett, 361(1-3), 184-187. doi:10.1016/j.neulet.2003.12.007

Song, X. J., Huang, Z. J., Song, W. B., Song, X. S., Fuhr, A. F., Rosner, A. L., . . Rupert, R. L. (2016). Attenuation Effect of Spinal Manipulation on Neuropathic and Postoperative Pain Through Activating Endogenous Anti-Inflammatory Cytokine Interleukin 10 in Rat Spinal Cord. J Manipulative Physiol Ther, 39(1), 42-53. doi:10.1016/j.jmpt.2015.12.004

Sparks, C. L., Liu, W. C., Cleland, J. A., Kelly, J. P., Dyer, S. J., Szetela, K. M., \& Elliott, J. M. (2017). Functional Magnetic Resonance Imaging of Cerebral Hemodynamic Responses to Pain Following Thoracic Thrust Manipulation in Individuals With Neck Pain: A Randomized Trial. J Manipulative Physiol Ther, 40(9), 625-634. doi:10.1016/j.jmpt.2017.07.010

Staud, R., Price, D. D., Robinson, M. E., Mauderli, A. P., \& Vierck, C. J. (2004). Maintenance of windup of second pain requires less frequent stimulation in fibromyalgia patients compared to normal controls. Pain, 110(3), 689-696. doi:10.1016/j.pain.2004.05.009

Staud, R., Vierck, C. J., Cannon, R. L., Mauderli, A. P., \& Price, D. D. (2001). Abnormal sensitization and temporal summation of second pain (wind-up) in patients with fibromyalgia syndrome. Pain, 91(1-2), 165-175. doi:10.1016/s0304-3959(00)00432-2

Teodorczyk-Injeyan, J. A., Injeyan, H. S., \& Ruegg, R. (2006). Spinal manipulative therapy reduces inflammatory cytokines but not substance $\mathrm{P}$ production in normal subjects. $J$ Manipulative Physiol Ther, 29(1), 14-21. doi:10.1016/j.jmpt.2005.10.002

Teodorczyk-Injeyan, J. A., McGregor, M., Triano, J. J., \& Injeyan, S. H. (2018). Elevated Production of Nociceptive CC Chemokines and sE-Selectin in Patients With Low Back Pain and the Effects of Spinal Manipulation: A Nonrandomized Clinical Trial. Clin $J$ Pain, 34(1), 68-75. doi:10.1097/AJP.0000000000000507

Teodorczyk-Injeyan, J. A., Triano, J. J., \& Injeyan, H. S. (2019). Nonspecific Low Back Pain: Inflammatory Profiles of Patients With Acute and Chronic Pain. Clin J Pain, 35(10), 818-825. doi:10.1097/AJP.0000000000000745

Thomson, O., Haig, L., \& Mansfield, H. (2009). The effects of high-velocity low-amplitude 
thrust manipulation and mobilisation techniques on pressure pain threshold in the lumbar spine. International Journal of Osteopathic Medicine, 12(2), 56-62.

Torebjork, H. E., Lundberg, L. E., \& LaMotte, R. H. (1992). Central changes in processing of mechanoreceptive input in capsaicin-induced secondary hyperalgesia in humans. $J$ Physiol, 448, 765-780. doi:10.1113/jphysiol.1992.sp019069

Treede, R. D., Rief, W., Barke, A., Aziz, Q., Bennett, M. I., Benoliel, R., . . Wang, S. J. (2019). Chronic pain as a symptom or a disease: the IASP Classification of Chronic Pain for the International Classification of Diseases (ICD-11). Pain, 160(1), 19-27. doi:10.1097/j.pain.0000000000001384

Urits, I., Burshtein, A., Sharma, M., Testa, L., Gold, P. A., Orhurhu, V., . . Kaye, A. D. (2019). Low Back Pain, a Comprehensive Review: Pathophysiology, Diagnosis, and Treatment. Curr Pain Headache Rep, 23(3), 23. doi:10.1007/s11916-019-0757-1

Valera-Calero, A., Lluch, E., Gallego-Izquierdo, T., Malfliet, A., \& Pecos-Martin, D. (2019). Endocrine response after cervical manipulation and mobilization in people with chronic mechanical neck pain: a randomized controlled trial. Eur J Phys Rehabil Med. doi:10.23736/S1973-9087.19.05475-3

Van Der Kleij, H. P., \& Bienenstock, J. (2007). Significance of Sensory Neuropeptides and the Immune Response. Psychoneuroimmunology, 1, 97.

Vase, L., Riley, J. L., 3rd, \& Price, D. D. (2002). A comparison of placebo effects in clinical analgesic trials versus studies of placebo analgesia. Pain, 99(3), 443-452. doi:10.1016/s0304-3959(02)00205-1

Vernon, H., Puhl, A., \& Reinhart, C. (2011). Systematic review of clinical trials of cervical manipulation: control group procedures and pain outcomes. Chiropr Man Therap, 19(1), 3. doi:10.1186/2045-709X-19-3

Vernon, H., Triano, J. J., Ross, J. K., Tran, S. K., Soave, D. M., \& Dinulos, M. D. (2012). Validation of a novel sham cervical manipulation procedure. Spine J, 12(11), 10211028. doi:10.1016/j.spinee.2012.10.009

Vlaeyen, J. W. S., Maher, C. G., Wiech, K., Van Zundert, J., Meloto, C. B., Diatchenko, L., . - . Linton, S. J. (2018). Low back pain. Nat Rev Dis Primers, 4(1), 52. doi:10.1038/s41572-018-0052-1

W.H.O. (2005). Guidelines on basic training and safety in chiropractic. Geneva, Switzerland: World Health Organization Retrieved from http $/ /$ www.who.int/medicines/areas/traditional/Chiro-Guidelines.pdf

Wager, T. D., Atlas, L. Y., Lindquist, M. A., Roy, M., Woo, C. W., \& Kross, E. (2013). An

This article is protected by copyright. All rights reserved 
fMRI-based ne urologic signature of physical pain. $N$ Engl J Med, 368(15), 1388-1397. doi:10.1056/NEJMoa1204471

Weber II, K. A., Wager, T. D., Mackey, S., Elliott, J. M., Liu, W. C., \& Sparks, C. L. (2019).

Evidence for decreased Neurologic Pain Signature activation following thoracic spinal manipulation in healthy volunteers and participants with neck pain. Neuroimage Clin, 24, 102042. doi:10.1016/j.nicl.2019.102042

Westlund, K. N., Kochukov, M. Y., Lu, Y., \& McNearney, T. A. (2010). Impact of central and peripheral TRPV1 and ROS levels on proinflammatory mediators and nociceptive behavior. Mol Pain, 6, 46. doi:10.1186/1744-8069-6-46

Whelan, T. L., Dishman, J. D., Burke, J., Levine, S., \& Sciotti, V. (2002). The effect of chiropractic manipulation on salivary cortisol levels. J Manipulative Physiol Ther, 25(3), 149-153. doi:10.1067/mmt.2002.122328

Willemen, H., Kavelaars, A., Prado, J., Maas, M., Versteeg, S., Nellissen, L. J. J., . . . Eijkelkamp, N. (2018). Identification of FAM173B as a protein methyltransferase promoting chronic pain. PLoS Biol, 16(2), e2003452. doi:10.1371/journal.pbio.2003452

Woolf, C. J. (1983). Evidence for a central component of post-injury pain hypersensitivity. Nature, 306(5944), 686-688. doi:10.1038/306686a0

Woolf, C. J. (2011). Central sensitization: implications for the diagnosis and treatment of pain. Pain, 152(3 Suppl), S2-15. doi:10.1016/j.pain.2010.09.030

Wu, L. J., Xu, H., Ko, S. W., Yoshimura, M., \& Zhuo, M. (2005). Feed-forward inhibition: a novel cellular mechanism for the analgesic effect of substance P. Mol Pain, 1, 34. doi:10.1186/1744-8069-1-34

Zhang, S., Zhao, E., \& Winkelstein, B. A. (2017). A Nociceptive Role for Integrin Signaling in Pain After Mechanical Injury to the Spinal Facet Capsular Ligament. Ann Biomed Eng, 45(12), 2813-2825. doi:10.1007/s10439-017-1917-2

This article is protected by copyright. All rights reserved 


\section{Figure Legend}

Figure 1. Pain mechanisms likely influenced by spinal manipulation (SM).

(a). In the periphery, SM may decrease pro-inflammatory cytokine responses (Roy et al., 2010; Teodorczyk-Injeyan et al., 2006, 2018) and oxidative stress (Duarte et al., 2019; Kolberg et al, 2015). (b) At the spinal segmental level, SM may induce segmental inhibition (Alonso-Perez et al., 2017; de Camargo et al., 2011; Dorron et al., 2016; Fernandez-Carnero et al., 2008; Fernandez-de-las-Penas et al., 2007; Fryer et al., 2004; Laframboise et al., 2016; Coronado et al., 2012; Honore et al., 2018; Millan et al., 2012, decrease temporal summation of pain (George et al., 2006; Bialosky et al., 2008, 2009, 2014; Bishop et al., 2011; Aspinall et al., 2019; Randoll et al. 2017), and inhibit central sensitization (Mohammadian et al., 2004; Song et al., 2016). (c) At the supraspinal level, no specific mechanism has been reported (Meyer et al., 2019), although widespread pain inhibition suggests cerebrospinal mechanisms involving the descending inhibitory system (Dorron et al., 2016; Salom-Moreno et al., 2014; Aspinall et al., 2019; Martinez-Segura et al., 2012). Changes in pain-related brain activity may reflect modulation of nociceptive activity at the spinal or supraspinal levels (Gay et al, 2014; Sparks et al., 2017; Weber II et al., 2019; Ellingsen et al., 2018).

This article is protected by copyright. All rights reserved 
Table 1. Hypoalgesic mechanisms of spinal manipulation

Mechanisms Effects on measured outcomes Supporting evidence

Decreased peripheral Reduction in plasmatic levels of oxydative stress ROS.

Duarte 2019; Kolberg 2015.

Decreased pro- Decline in production of CCL3

inflammatory cytokine and CCL4 chemokines, TNF- $\alpha$

response

and IL- $1 \beta$.

Teodorczyk-Injeyan 2006, 2018;

Roy 2010.

Segmental inhibition of

Segmental (dermatomal and

nociceptive processes

myotomal) increase of pressure pain thresholds.

Coronado 2012; Honore 2018; Millan

2012; Alonso-Perez 2017; Fryer

2004; de Camargo 2011; Dorron

2016; Fernandez-Carnero 2008;

Fernandez-de-las-Penas 2007;

Laframboise 2016; Duarte 2019;

Grayson 2012; Onifer 2015; Onifer

2018; Nim 2020.

Reduction in pain evoked by repeated thermal and electrical

Aspinall 2019b; Bialosky 2008,

Inhibition of temporal

summation

stimuli. 2009b, 2014; Bishop 2011a; George

2006; Randoll 2017.

Reduction of spontaneous pain, secondary hyperalgesia, and

Inhibition of central

sensitization

allodynia induced by topical

Mohammadian 2004; Song 2016.

capsaicin. Increased spinal levels

of IL- 10 .

This article is protected by copyright. All rights reserved 
Table 2. Active interventions and placebo used in the spinal manipulation (SM) studies

\begin{tabular}{|c|c|c|c|c|c|}
\hline Authors & Year & Sample & Active SM intervention & Placebo SM intervention & Non-placebo control interventions \\
\hline Kovanur-Sampath K, et al. & 2017 & $\mathrm{~N}=24$ Humans & HVLA SM T5 & SM positioning, no thrust & - \\
\hline Plaza-Manzano G, et al. & 2014 & $\mathrm{~N}=30$ Humans & HVLA SM C $4-5$ or T3-5 & - & No intervention \\
\hline Valera-Calero A, et al. & 2019 & $\mathrm{~N}=83$ Humans & HVLA SM cervical & SM positioning, no thrust & - \\
\hline Whelan TL, et al. & 2002 & $\mathrm{~N}=30$ Humans & HVLA SM cervical & SM positioning, no thrust & No intervention (supine position) \\
\hline Lohman EB, et al & 2019 & $\mathrm{~N}=28$ women & HVLA SM cervical & SM positioning, no movement, no thrust & - \\
\hline Molina-Ortega $\mathrm{F}$, et al. & 2014 & $\mathrm{~N}=30$ Humans & HVLA SM C $5-6$ or T4 & SM positioning, no thrust & - \\
\hline Duarte FCK, et al. & 2019 & $\mathrm{~N}=30$ Rats & HVLA SM instrument L4-5 & Lighter SM force, no preload & - \\
\hline Kolberg C, et al & 2015 & $\mathrm{~N}=23$ Humans & 10 sessions HVLA SM full spine & - & - \\
\hline Roy RA, et al. & 2010 & $\mathrm{~N}=21$ Humans & HVLA SM instrument lumbar & - & No intervention (leg length evaluation) \\
\hline Teodorczyk-Injeyan JA, et al. & 2018 & $\mathrm{~N}=63$ Humans & 6 sessions HVLA SM lumbosacral & - & - \\
\hline Teodorczyk-Injeyan JA, et al. & 2006 & $\mathrm{~N}=64$ Humans & HVLA SM thoracic & SM with different position and force orientation & No intervention (venipuncture) \\
\hline Alonso-Perez JL, et al. & 2017 & $\mathrm{~N}=75$ Humans & HVLA SM C7 & - & HVLA to C5. Right lateral glide mobilizations \\
\hline Bialosky JE, et al. & 2008 & $\mathrm{~N}=60$ Humans & HVLA SM lumbar & - & HVLA with positive, negative or neutral expectations \\
\hline Bialosky JE, et al. & 2009 & $\mathrm{~N}=36$ Humans & 4 HVLA SM pelvis & - & Stationary bike. Extension exercises \\
\hline de Camargo VM, et al. & 2011 & $\mathrm{~N}=37$ Humans & HVLA SM C5-6 & - & No intervention \\
\hline Dorron SL, et al. & 2016 & $\mathrm{~N}=34$ Humans & HVLA SM L5-S1 & - & Comparison of right and left sides \\
\hline Fernandez-Carnero J, et al. & 2008 & $\mathrm{~N}=10$ Humans & HVLA SM cervical & Manual contact & - \\
\hline Fernandez-de-las-Penas C, et al. & 2007 & $\mathrm{~N}=15$ Humans & HVLA SM C 5-6 & SM positioning with no tissue tension, no thrust & - \\
\hline Fryer G, et al. & 2008 & $\mathrm{~N}=96$ Humans & HVLA SM thoracic & Sham laser acupuncture & Extension mobilization \\
\hline George SZ, et al. & 2006 & $\mathrm{~N}=60$ Humans & HVLA SM humbar & - & Stationary bike. Extension exercises \\
\hline Laframboise MA, et al. & 2016 & $\mathrm{~N}=26$ Humans & HVLA SM C5-6 drop-table & $\begin{array}{l}\text { SM positioning and preload, } \\
\text { thrust into headpiece by supporting hand }\end{array}$ & - \\
\hline Salom-Moreno J, et al. & 2014 & $\mathrm{~N}=52$ Humans & HVLA SM T3-6 & - & Posteroanterior mobilization \\
\hline Aspinall SL, et al. & 2019 & $\mathrm{~N}=80$ Humans & HVLA SM L5 & Lighter SM with extraspinal thrust & - \\
\hline Honore $\mathrm{M}$, et al. & 2020 & $\mathrm{~N}=50$ Humans & HVLA SM T5 prone & Lighter SM with extraspinal thrust & - \\
\hline Nim CG, et al. & 2020 & $\mathrm{~N}=132$ Humans & HVLA SM lumbar & - & HVLA to stiffest or more sensitive segment \\
\hline Grayson JE, et al. & 2012 & $\mathrm{~N}=12$ Rats & $3 \times 1$ min mobilizations L5 & Manual contact & - \\
\hline Onifer SM, et al. & 2015 & $\mathrm{~N}=24$ Rats & 10 min LVVA SM L5 & - & No intervention \\
\hline Onifer SM, et al. & 2018 & $\mathrm{~N}=27$ Rats & 10 min LVVA SM L5 & - & No intervention (table positioning) \\
\hline Bialosky JE, et al. & 2014 & $\mathrm{~N}=110$ Humans & HVLA SM lumbar & SM positioning, no thrust & No intervention \\
\hline Bishop MD, et al. & 2011 & $\mathrm{~N}=90$ Humans & HVLA SM thoracic & - & Cervical flexion exercise. Rest for $5 \mathrm{~min}$ \\
\hline Randoll C, et al. & 2017 & $\mathrm{~N}=31$ Humans & HVLA SM T4 & Light mechanical stimulus & No intervention \\
\hline Mohammadian $\mathrm{P}$, et al. & 2004 & $\mathrm{~N}=20$ Humans & HVLA SM thoracic & SM positioning, no thrust & - \\
\hline Song XJ, et al. & 2016 & $\mathrm{~N}=96$ Rats & HVLA SM instrument L5 & - & Force settings 1 and 2. No intervention \\
\hline Casanova-Méndez $\mathrm{A}$, et al. & 2014 & $\mathrm{~N}=60$ Humans & HVLA SM T4 & - & Two techniques were compared \\
\hline Martínez-Segura $\mathrm{R}$, et al. & 2012 & $\mathrm{~N}=90$ Humans & HVLA SM C $3-4$ or T1-4 & - & Comparison of two levels and laterality \\
\hline Gay CW, et al. & 2014 & $\mathrm{~N}=24$ Humans & HVLA SM lumbar & Manual contact & Mobilization \\
\hline Sparks CL, et al. & 2017 & $\mathrm{~N}=24$ Humans & HVLA SM thoracic & SM positioning, no thrust & - \\
\hline Weber II KA, et al. & 2019 & $\mathrm{~N}=24$ Humans & HVLA SM T4-5 & SM positioning, no thrust & - \\
\hline Ellingsen DM, et al. & 2018 & $\mathrm{~N}=31$ Humans & HVLA SM lumbar & - & Mobilization \\
\hline Bishop MD, et al. & 2011 & $\mathrm{~N}=112$ Humans & HVLA SM lumbar & Lower velocity SM or no thrust & - \\
\hline Bishop MD, et al & 2017 & $\mathrm{~N}=60$ Humans & HVLA SM lumbar & Manual contact for $5 \mathrm{~min}$ & - \\
\hline
\end{tabular}

$S M=$ Spinal Manipulation $; H V L=$ High Velocity Low Amplitude LVVA = Low Velocity Variable Amplitude 
